\title{
Testing corrections for paleomagnetic inclination error in sedimentary rocks: A comparative approach
}

\author{
Lisa Tauxe ${ }^{\mathrm{a}, *}$, Kenneth P. Kodama ${ }^{\mathrm{b}}$, Dennis V. Kent ${ }^{\mathrm{c}, \mathrm{d}}$ \\ a Scripps Institution of Oceanography, La Jolla, CA 92093-0220, United States \\ ${ }^{\mathrm{b}}$ Lehigh University, Bethlehem, PA, United States \\ ${ }^{\text {c }}$ Earth and Planetary Sciences, Rutgers University, Piscataway, NJ 08854, United States \\ d Lamont Doherty Earth Observatory, Palisades, NY 10964, United States
}

\section{A R T I C L E I N F O}

\section{Article history:}

Received 1 February 2008

Received in revised form 27 April 2008

Accepted 7 May 2008

\section{Keywords:}

Paleosecular variation models

Geomagnetic field behavior

Inclination flattening (shallowing)

Magnetic anisotropy

\begin{abstract}
A B S T R A C T
Paleomagnetic inclinations in sedimentary formations are frequently suspected of being too shallow. Recognition and correction of shallow bias is therefore critical for paleogeographical reconstructions. This paper tests the reliability of the elongation/inclination $(E / I)$ correction method in several ways. First we consider the $E / I$ trends predicted by various PSV models. We explored the role of sample size on the reliability of the $E / I$ estimates and found that for data sets smaller than $\sim 100-150$, the results were less reliable. The Giant Gaussian Process-type paleosecular variation models were all constrained by paleomagnetic data from lava flows of the last five million years. Therefore, to test whether the method can be used in more ancient times, we compare model predictions of $E / I$ trends with observations from five Large Igneous Provinces since the early Cretaceous (Yemen, Kerguelen, Faroe Islands, Deccan and Paraná basalts). All data are consistent at the $95 \%$ level of confidence with the $E / I$ trends predicted by the paleosecular variation models. The Paraná data set also illustrated the effect of unrecognized tilting and combining data over a large latitudinal spread on the $E / I$ estimates underscoring the necessity of adhering to the two principle assumptions of the method. Then we discuss the geological implications of various applications of the $E / I$ method. In general the $E / I$ corrected data are more consistent with data from contemporaneous lavas, with predictions from the well constrained synthetic apparent polar wander paths, and other geological constraints. Finally, we compare the $E / I$ corrections with corrections from an entirely different method of inclination correction: the anisotropy of remanence method of Jackson et al. [Jackson, M.J., Banerjee, S.K., Marvin, J.A., Lu, R., Gruber, W., 1991. Detrital remanence, inclination errors and anhysteretic remanence anisotropy: quantitative model and experimental results. Geophys. J. Int. 104, 95-103] which relies on measurement of remanence and particle anisotropies of the sediments. In the two cases where a direct comparison can be made, the two methods give corrections that are consistent within error. In summary, it appears that the $E / I$ method for recognizing and corrected the effects of sedimentary flattening is reasonably robust for at least the Mesozoic and Cenozoic when the source of scatter is geomagnetic and sedimentary flattening in origin.
\end{abstract}

(C) 2008 Elsevier B.V. All rights reserved.

\section{Introduction}

The fact that the Earth's magnetic field can be used to estimate latitude has been known since 1600 and the publication of De Magnete by William Gilbert who proclaimed

"We may see how far from unproductive magnetick philosophy is, how agreeable, how helpful, how divine! Sailors when tossed about on the waves with continuous cloudy weather, and unable by means of the celestial luminaries to learn anything

\footnotetext{
* Corresponding author.

E-mail address: Itauxe@ucsd.edu (L. Tauxe).
}

about the place or the region in which they are, with a very slight effort and with a small instrument are comforted, and learn the latitude of the place." [translated by S.P. Thompson; Gilbert (1600)].

Gilbert knew that the field was not exactly dipolar, but deviated significantly from that of a geocentric axial dipole (GAD) field, although he thought these deviations were controlled by features of the crust and were permanent. In 1634, Gellibrand demonstrated that these deviations, or "secular variations" changed over time. If averaged over sufficient time ( $\sim 10,000$ years), the geomagnetic field can be reasonably well approximated by a GAD field (e.g., Irving, 1960), an approximation that lies at the heart of much of paleomagnetic research over the last 50 years. 


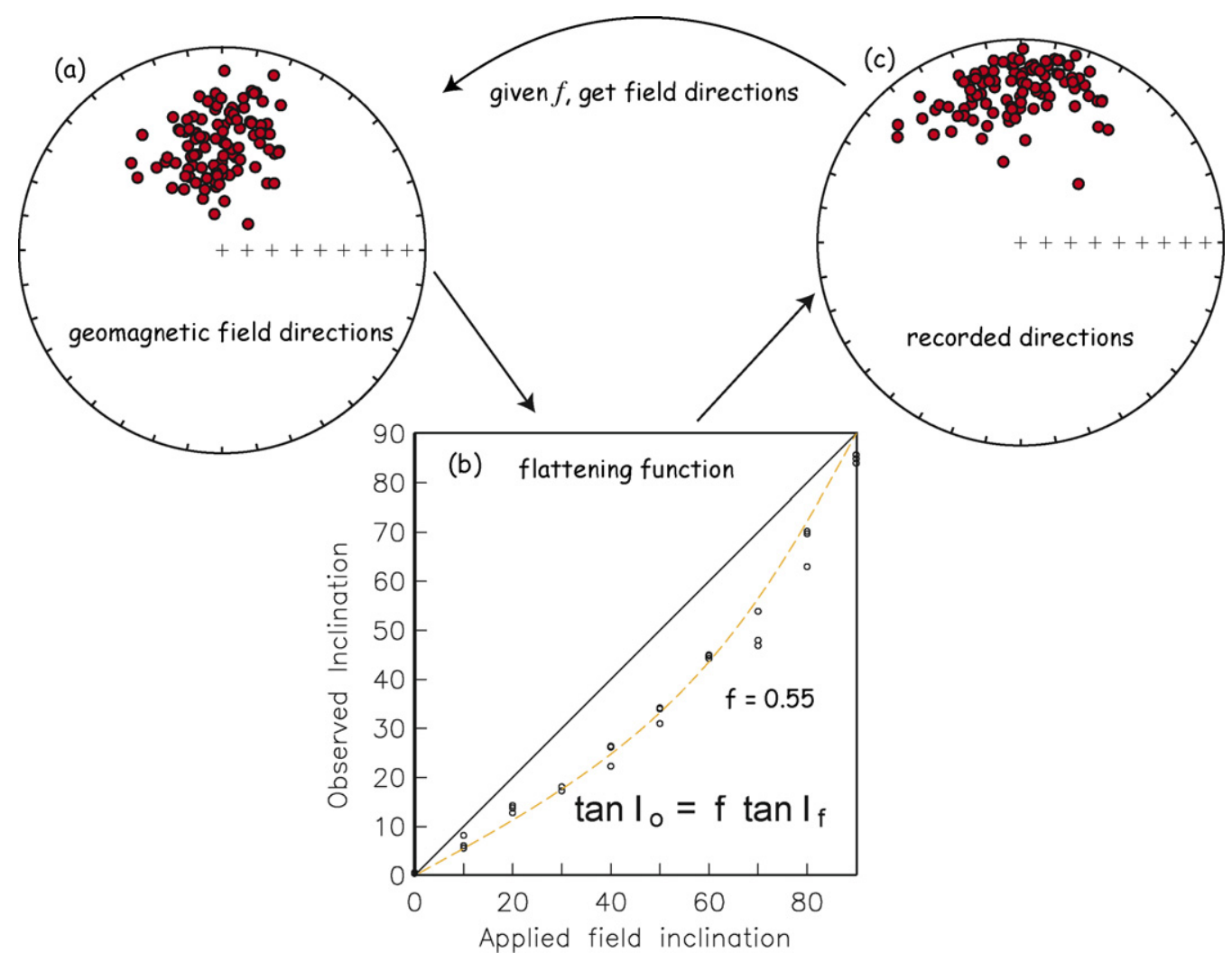

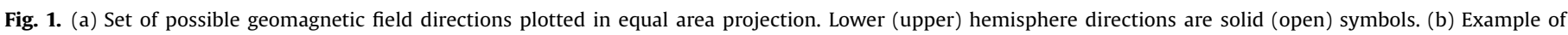
sedimentary flattening (data are of redeposited sediments from Tauxe and Kent, 1984). (c) Directions recorded by the sediment using the flattening function in (b).

The so-called "dipole formula" relates the inclination $I$ of the ancient magnetic field to the latitude $\lambda$ by $\tan I=2 \tan \lambda$. As continents move, the pole of this GAD field appears to wander in the continental reference frame, hence the pursuit of "apparent polar wander paths" or APWPs which in turn can be used to reconstruct paleolatitudes of continental fragments through time.

In order to construct APWPs, paleomagnetists have made extensive use of paleomagnetic data from sedimentary rocks. A glance at a recent synthesis of paleomagnetic poles and APWPs for the last 200 Myr by Besse and Courtillot (2002) shows that data from sedimentary rocks make up a large proportion of the results. Yet it has long been recognized that while many sedimentary records faithfully represent the magnetic field inclination (e.g., Opdyke and Henry, 1969), many suffer from inclination flattening (e.g., King, 1955).

Geomagnetic field directions (e.g., Fig. 1a) with inclinations $I_{\mathrm{f}}$ are recorded in sediments with observed inclinations $\left(I_{0}\right)$ following the flattening function of King (1955), $\tan I_{\mathrm{o}}=f \tan I_{\mathrm{f}}$, where $\mathrm{f}$ is the flattening factor (Fig. 1b) ranging from unity (no flattening) to 0 (completely flattened). Examples of the recorded "flattened" directions are shown in Fig. 1c. Note that flattened directions tend to become elongate in the horizontal plane, a feature that distinguishes this cause of inclination shallowing from others, for example, poleward plate motion which leaves the distribution unchanged or non-dipole field effects. Axial non-dipole field contributions like the axial quadrupole or octupole make the distribution more elongate in the meridional plane (see, e.g., Tauxe and Kent 2004). Sedimentary flattening has long been recognized as a possible problem especially in red beds (e.g., Bressler and Elston, 1980; Lovlie and Torsvik, 1984; Tauxe and Kent, 1984), although it has proved a problem in other types of sediments as well (e.g., Tarduno, 1990; Krijgsman and Tauxe, 2004).
When using sedimentary data to constrain paleolatitudes there are two key questions: "How can we recognize data that are biased by inclination flattening?" and "What can be done to correct the bias?" In principle, if we know that a given data set has flattened inclinations and we could assume a value for $f$, we could invert the flattening formula to calculate the inclination of the applied field by

$\tan I_{\mathrm{f}}=\left(\frac{1}{f}\right) \tan I_{\mathrm{o}}$

Unfortunately, values of $f$ in laboratory redeposition experiments and in nature vary from near zero to unity. Alternatively, if the distribution of the original geomagnetic field directions were known (for example, if the set of directions could be assumed circularly symmetric, or elongate in some known way), the flattening factor yielding the expected distribution could be used to correct the inclinations and derive the original directions.

The focus of this paper is the so-called 'elongation/inclination' or E/I method (Tauxe and Kent, 2004) for recognizing and correcting inclination flattening. This method compares the symmetry of directional datasets with those predicted by statistical paleosecular variation models. As we shall see, these predict directions that are elongate in the up-down plane at the equator (where inclinations are quasi-horizontal) and circularly symmetric at the poles (where inclinations are quasi-vertical). The E/I method of Tauxe et al. (2004) exploits the trend predicted from their PSV model (TK03) by adjusting the average value of $f$ until the resulting "corrected" directions have an elongation and inclination consistent with that predicted by the paleosecular variation field model.

The $E / I$ correction method depends on several key assumptions: (1) the scatter observed in the paleomagnetic directions derives from only two sources: variations in the geomagnetic field and sed- 
imentary flattening following the flattening formula and (2) the distributions of directions generated by geomagnetic field variations are known. Statistical PSV models can predict trends of elongation versus inclination, and the model used by Tauxe and Kent (2004) is one of many. Therefore, a critical question is "How well is the $E / I$ trend constrained?" In this paper, we will first discuss E/I trends predicted by various PSV models. Then we will assess whether the $E / I$ trend has remained reasonably constant through geologic time. Finally, we will compare results obtained by the E/I method with a completely independent method for correction inclination flattening, the "remanence anisotropy" correction method originally proposed by Jackson et al. (1991).

\section{Models for paleosecular variation}

The earliest model of secular variation of the Earth's magnetic field is the "dipole wobble" model of Creer et al. (1959) (subsequently named Model B by Irving and Ward, 1963). Dipole wobble (simulated by random variations in the three dipole terms of the spherical harmonic expansion of the geomagnetic field) produces Fisher (1953) distributed sets of virtual geomagnetic poles (VGPs) that average to the spin axis. Creer et al. (1959) pointed out that directions from such a set of VGPs would not be circularly symmetric, but oval and also pointed out that the dispersion factor of the directions would be latitude dependent with the highest scatter at the equator. In fact, Creer (1962) compiled data from lava flows which were consistent with a dipole wobble model for secular variation with a Fisher concentration parameter $\kappa$ of about 35 , yielding angular dispersions in directions varying from about 20 at the equator to about 10 at $60^{\circ} \mathrm{N}$.

A simpler model for PSV, proposed by Irving and Ward (1963) who named it Model A envisions secular variation as arising from adding random directional perturbations drawn from a uniform distribution to the expected dipole direction. Directions arising from such a process would be circularly symmetric (although not necessarily Fisher distributed) and the VGP distribution would be oval at the equator and become more circular toward the poles.

We will be discussing PSV models based on what is called a "Giant Gaussian Process" later in the paper. These derive ultimately from Model B, producing circularly symmetric (although not exactly Fisher distributed) VGP distributions, hence more or less elongate distributions of directions depending on latitude. To gain some insight into how VGP scatter and Model B-type secular variation translates into directional dispersion, consider a set of Fisher distributed VGPs with a $\kappa$ of 20 . Converting these to directions observed at the equator and finding the eigenvalues $\left(\tau_{i}\right)$ of the orientation matrix (see, e.g., Tauxe et al., 2004 for computational details) allows us to calculate the elongation $E$ as the ratio of the intermediate to least eigenvalues $\left(\tau_{2} / \tau_{3}\right)$ as discussed by Tauxe et al. (2004), which in this case will be about 3.1. Taking a more concentrated set of VGPs with $\kappa=100$, we find the directions are more elongate with $E=3.6$.

It may seem counter intuitive that tighter distributions of VGPs make more elongate equatorial directional distributions. It makes sense, however, if you consider that really scattered results will be circularly symmetric (as uniform distributions are). As the distributions of VGPs become more scattered, so do the directions and as the VGPs approach a uniform distribution, the directions get more circular.

Beck (1999) used the ratio of semi-axes of Bingham (1964) confidence ellipses to quantify elongation of directional distributions. It is worth mentioning that $E$ (as defined by Tauxe, 1998) is not the same thing, although the ellipse axes for both Kent (1982) and Bingham (1964) confidence ellipses derive from the eigenvalues.
The calculation for Kent ellipses is more straightforward than for Bingham ellipses, so we will explore the relationship between $E$ and semi-axis ratios using Kent ellipses. The major $\left(\zeta_{95}\right)$ and $\operatorname{minor}\left(\eta_{95}\right)$ semi-axes of the $95 \%$ confidence ellipse relate to the eigenvalues by

$\zeta_{95}=\sin ^{-1}\left(\sqrt{g} \tau_{2}\right), \quad \eta_{95}=\sin ^{-1}\left(\sqrt{g} \tau_{3}\right)$

where $g=-2 \ln (.05) /\left(R^{2} / N\right)$ and $R$ is the resultant vector of $N$ unit vectors. To see how the ratio of these relate to elongation, we can use simulated data sets. If we draw 100 directions from a Fisher distribution with a horizontal mean inclination and $\kappa=20$, in a typical sample, the resultant vector $R=96.6215$ and the Kent ellipse is very nearly circular (as expected) with semi-axes of about $3^{\circ}$. When we convert these directions to VGPs (assuming an equatorial latitude) and calculated the Kent ellipse of the VGPs, the ratio of the semiaxes is about $2: 1$, whereas the ratio of the eigenvalues themselves (elongation as we have defined it or $\tau_{2} / \tau_{3}$ ) is about 4 . In this example, $\sqrt{g}=0.25$ and $\tau_{2}$ and $\tau_{3}$ are 0.0530 and 0.0126 , respectively. These values give $\zeta_{95}=3.3, \eta=1.6$ for a ratio of $\sim 2: 1$, a consequence of the non-linear transformation between eigenvalues and confidence ellipses.

Returning to the problem of secular variation, McElhinny and Merrill (1975) chronicle the development of a series of models (C, D and $\mathrm{M}$ ) that combine aspects of dipole wobble (B-type models) and non-dipole field contributions (A-type models). They also updated the compilation of paleomagnetic directions from lava flows of the last five million years and showed that VGP dispersion (as opposed to directional dispersion) varied as a function of latitude with the highest scatter at the poles. A useful measure of scatter in the predicted distributions is the angular standard deviation of the scatter of the VGPs. Cox (1969) defined a parameter $S$ as

$S^{2}=(N-1)^{-1} \sum_{i=1}^{N}\left(\Delta_{i}\right)^{2}$

where $N$ is the number of observations and $\Delta$ is the angle between the $i$ th VGP and the spin axis. Model M characterized the latitudinal dependence of $S$ as an increasing ratio of non-dipole field to dipole field as a function of latitude.

Model G of McFadden et al. (1988) took a different approach to account for the same observation of increasing VGP scatter with latitude by separating the geomagnetic field into the two families of Roberts and Stix (1972), the dipole family in which the Gauss coefficients $\left(g_{l}^{m}, h_{l}^{m}\right)$ produce fields that are antisymmetric about the equator (those with $l$-modd) and the "quadrupole family" in which the Gauss coefficients produce fields that are symmetric about the equator (those with $l-m$ even). The antisymmetric terms contribute more strongly to scatter in VGPs with latitude than the symmetric terms. Model G thus has the form:

$S^{2}=(a \lambda)^{2}+b^{2}$

where $a$ and $b$ are the antisymmetric and symmetric family coefficients, respectively and $\lambda$ is latitude. McFadden et al. (1988) found that values of $a=0.26 \pm 0.02$ and $b=1.8 \pm 0.7$ provided a good fit to their "better quality" dual polarity data set representing the last five million years.

Paleosecular variation models of the form of Eq. (2) predict average scatter as a function of latitude, but do not predict distributions of field vectors which would allow us to investigate the effect of flattening on paleomagnetic observations. What we require instead is a statistical PSV model and there have been several that build on the simple idea of Model B. The first and most influential of these was the PSV model of Constable and Parker (1988) here called CP88. CP88 models the time varying geomagnetic field as a Giant Gaus- 
Table 1

Parameters for various PSV models

\begin{tabular}{|c|c|c|c|c|c|c|}
\hline Parameter & CP88 & CJ98 & QC96 & TK03.GAD & TK03. $\mathrm{g}_{2}{ }^{0}$ & $\mathrm{TK}^{2} 03 . \mathrm{g}_{3}{ }^{0}$ \\
\hline $\bar{g}_{1}^{0}$ & $-30 \mu \mathrm{T}$ & $-30 \mu \mathrm{T}$ & $-30 \mu \mathrm{T}$ & $-18 \mu \mathrm{T}$ & $-18 \mu \mathrm{T}$ & $-18 \mu \mathrm{T}$ \\
\hline $\bar{g}_{2}^{0}$ & $-1.8 \mu \mathrm{T}$ & $-1.5 \mu \mathrm{T}$ & $-1.2 \mu \mathrm{T}$ & 0 & $.09 \mu \mathrm{T}$ & 0 \\
\hline $\bar{g}_{3}^{0}$ & 0 & & 0 & 0 & 0 & $3.6 \mu \mathrm{T}$ \\
\hline$\alpha$ & $27.7 \mu \mathrm{T}$ & $15 \mu \mathrm{T}$ & $27.7 \mu \mathrm{T}$ & $7.5 \mu \mathrm{T}$ & $7.5 \mu \mathrm{T}$ & $7.5 \mu \mathrm{T}$ \\
\hline$\beta$ & & & & 3.8 & 3.8 & 3.8 \\
\hline$\sigma_{1}^{0}$ & $0.5 \sigma_{l}=3 \mu \mathrm{T}$ & $3.5 \sigma_{l}=11.72 \mu \mathrm{T}$ & $3 \mu \mathrm{T}$ & $\beta \sigma_{l}=6.4 \mu \mathrm{T}$ & $\beta \sigma_{l}=6.4 \mu \mathrm{T}$ & $\beta \sigma_{l}=6.4 \mu \mathrm{T}$ \\
\hline$\sigma_{1}^{1}$ & $0.5 \sigma_{l}=3 \mu \mathrm{T}$ & $0.5 \sigma_{l}=1.67 \mu \mathrm{T}$ & $3.0 \mu \mathrm{T}$ & $\sigma_{l}=1.7 \mu \mathrm{T}$ & $\sigma_{l}=1.7 \mu \mathrm{T}$ & $\sigma_{l}=1.7 \mu \mathrm{T}$ \\
\hline$\sigma_{2}^{0}, \sigma_{2}^{2}$ & $\sigma_{l}=2.14 \mu \mathrm{T}$ & $\sigma_{l}=1.16 \mu \mathrm{T}$ & $1.3 \mu \mathrm{T}$ & $\sigma_{l}=0.6 \mu \mathrm{T}$ & $\sigma_{l}=0.6 \mu \mathrm{T}$ & $\sigma_{l}=0.6 \mu \mathrm{T}$ \\
\hline$\sigma_{2}^{1}$ & $\sigma_{l}=2.14 \mu \mathrm{T}$ & $3.5 \sigma_{l}=4.06 \mu \mathrm{T}$ & $4.3 \mu \mathrm{T}$ & $\beta \sigma_{l}=2.2 \mu \mathrm{T}$ & $\beta \sigma_{l}=2.2 \mu \mathrm{T}$ & $\beta \sigma_{l}=2.2 \mu \mathrm{T}$ \\
\hline$l-$ modd & $\sigma_{l}$ & $\sigma_{l}$ & $\sigma_{l}$ & $\beta \sigma_{l}$ & $\beta \sigma_{l}$ & $\beta \sigma_{l}$ \\
\hline$l$-meven & $\sigma_{l}$ & $\sigma_{l}$ & $\sigma_{l}$ & $\sigma_{l}$ & $\sigma_{l}$ & $\sigma_{l}$ \\
\hline$c / a=0.547$ & \multicolumn{6}{|c|}{$\sigma_{l}^{2}=(c / a)^{2 l} \alpha^{2} /[(l+1)(2 l+1)]$} \\
\hline
\end{tabular}

sian Process (GGP) whereby the Gauss coefficients $g_{l}^{m}, h_{l}^{m}$ (except for the axial dipole term, $g_{1}^{0}$ and the axial quadrupole term $g_{2}^{0}$ ) have zero mean and standard deviations that are a function of degree $l$. For $l \geq 2$ these standard deviations are given by

$\sigma_{l}^{2}=\frac{(c / a)^{2} l \alpha^{2}}{(l+1)(2 l+1)}$

where $c / a$ is the ratio of the core radius to that of Earth and $\alpha$ is a fitted parameter. The parameters used in the model of CP88 are listed in Table 1.

The advantage of using a statistical model like CP88 is that distributions of directions can be generated and compared with the paleomagnetic observations and with other model predictions. One simply draws coefficients for a field model from gaussian distributions with the specified means and standard deviations and calculates the geomagnetic elements at a given position using the usual formulae. The main disadvantage of the CP88 model in particular is that it predicts that the dispersion of VGPs is virtually independent of the latitude of observation, yet most data compilations seem to suggest a strong latitudinal dependence of VGP scatter (see, e.g., McFadden et al., 1988; McElhinny and McFadden, 1997), although there is currently some discussion of whether this is, in fact, true (see Johnson et al., 2008).

As noted by McFadden et al. (1988), Gauss coefficients that are antisymmetric about the equator contribute more strongly to scatter in VGPs at higher latitude than those that are symmetric about the equator. So to improve the fit of the statistical paleosecular variation model to their compilation of paleomagnetic observations, Quidelleur (1996) modified the CP88 model by decreasing the variance in the $\sigma_{2}^{0}$ (symmetric) term and increasing the variance in the $\sigma_{2}^{1}$ (antisymmetric) terms relative to the CP88 model (see QC96 in Table 1). Similarly, Constable and Johnson (1999) incorporated larger variance in the axial-dipole, and in the non-axial-quadrupole Gauss coefficients, $g_{1}^{0}$ and $h_{2}^{1}$ (see CJ98 in Table 1 ). All of these models assign the dipole term special status with increased importance relative to the other terms. In contrast, the most recent of statistical PSV model, that of Tauxe et al. (2004), does not assign special status to the axial dipole, but adjusts the power in all the antisymmetric Gauss coefficients (including the axial dipole) relative to all the symmetric ones with a constant factor $\beta$. They also adjusted the average strength of the axial dipole term to fit the observed Cenozoic average of Selkin and Tauxe (2000), a change that has no bearing on the current discussion (see TK03.GAD in Table 1).

Another difference among the various models is the treatment of the axial quadrupole term. Most models have a small, non-zero mean up to $6 \%$ of the dipole term (e.g., CP88). Some low latitude data sets (e.g., Brunhes data of Schneider and Kent, 1990) show no significant deviation from GAD, while others (e.g., Matuyama data of Schneider and Kent, 1990 and lava flow data of Opdyke et al., 2006) show some deviation consistent with a non-zero average for the axial quadrupole term. Thus it seems possible that the quadrupole term has long term variations and more low latitude data are necessary to constrain future models.

Each of the GGP models was designed to fit a slightly different set of paleosecular variation data and the process of database assembly is ongoing (see, e.g., Johnson et al., 2008 and references therein). Khokhlov et al. (2001) developed a statistical test for predictions from the various GGP models against a given dataset which was improved upon by Khokhlov et al. (2006). Testing various PSV models against the data compilation of Quidelleur (1996) showed that all but QC96 could be rejected as being incompatible with the QC96 data set. This may not be surprising or even worrisome, as only the QC96 model was designed specifically to fit the QC96 data compilation. However, as the database improves, the statistical test of Khokhlov et al. (2006) will be a very important tool for selecting the "best" model.

The major differences among the data sets that were used to constrain the various PSV models are selection criteria (demagnetization procedures, internal consistency at a site level and exclusion of "deviant" VGPs using some cutoff value). Ideally, we would use no VGP cutoff, but the interest of the paleomagnetic community in unusual field states (reversals and excursions) has resulted in their over-representation in the database. Some data compilations have used a fixed cutoff for VGP latitude (e.g., $45^{\circ}$ ), which biases against the more scattered data collected at higher latitude, or a variable VGP cutoff (e.g., Vandamme, 1994) which performs rather unevenly, depending on the characteristics of the data. In any case, to compare predictions with observations, the model predictions must be trimmed in the same way as the data sets and it is not clear that Khokhlov et al. (2006) trimmed the model predictions in accordance with the selection criteria inherent in the data set they used.

\section{Robustness of $E / I$ predictions}

\subsection{Trends predicted by different PSV models}

Our interest here is in predictions of $E / I$ trends using the statistical PSV model approach. For this purpose, we can create a number of field models through a Monte Carlo process whereby Gauss coefficients are drawn from the distributions defined by the parameters in Table 1. These in turn, predict directions at specified latitudes (longitudes are assumed zero for these zonally symmetric models). For each model, we simulated 10,000 field models and calculated directions at ten degree latitude intervals from the equator to the (north) pole. Best fit coefficients for $E / I$ trend $\left(E=a+b I+c I^{2}+d I^{3}\right)$ are listed in Table 2. Those for TK03 are slightly different from the ones calculated by Tauxe et al. (2004) because we have redone all 
Table 2

Predicted coefficients for the Elongation/Inclination trend for various PSV models

\begin{tabular}{llrrr}
\hline Model & $a$ & \multicolumn{1}{l}{$b$} & \multicolumn{1}{l}{$c$} \\
\hline CP88 & 2.920 & $8.309 \times 10^{-3}$ & $-8.941 \times 10^{-4}$ & $6.281 \mathrm{e}-06$ \\
QC96 & 2.944 & $3.192 \times 10^{-3}$ & $-9.312 \times 10^{-4}$ & $7.374 \mathrm{e}-06$ \\
CJ98 & 2.806 & $-1.082 \times 10^{-3}$ & $-7.918 \times 10^{-4}$ & $6.567 \mathrm{e}-06$ \\
TK03.GAD & 2.895 & $-1.466 \times 10^{-2}$ & $-3.525 \times 10^{-4}$ & $3.160 \mathrm{e}-06$ \\
TK03.G20 & 2.842 & $-5.961 \times 10^{-3}$ & $-6.023 \times 10^{-4}$ & $4.968 \mathrm{e}-06$ \\
GR99.E & 3.695 & $-4.991 \times 10^{-2}$ & $2.017 \times 10^{-4}$ & $-1.263 \mathrm{e}-07$ \\
GR99.G & 2.593 & $-4.248 \times 10^{-3}$ & $-1.694 \times 10^{-4}$ & $1.244 \mathrm{e}-07$ \\
\hline
\end{tabular}

Best fit coefficients for $E / I$ equation: $E=a+b I+c I^{2}+d I^{3}$.

the simulations for this paper in a consistent manner with a larger set of field models. We also note that the polynomial printed in Table 2 of Tauxe et al. (2004) was incorrect. The new coefficients are in fact quite similar to those calculated from the data in their Table 2 (which is: $E=2.91-0.015 I-.00035 I^{2}$ ).

For the purposes of this paper, we are not truncating the directions or VGPs with any arbitrary cutoff. Cutoffs (e.g., Vandamme, 1994) are designed to rectify the tendency to oversample excursions and reversals in paleomagnetic studies. As statistical and numerical field models place no particular emphasis on sampling unusual field states, we are treating the field behavior as a continuum and including the excursions and reversals as part of the secular variation process. The value for $S$ for TK03.GAD for the VGPs predicted for $90^{\circ}$ is 22.7 . For comparison, the scatter parameter using a $45^{\circ}$ colatitude cutoff is 19.8 and the variable cutoff of Vandamme (1994) (colatitude $=38.7^{\circ}$ ) is $18.7^{\circ}$.

$E / I$ trends for various PSV models listed in Table 2 are shown in Fig. 2. We also show the trend predicted by Model B using a value for $\kappa$ of 35 as originally proposed. In addition to TK03.GAD in which all the non-axial dipole terms have zero mean, we show one other variant: TK03.g20 in which the axial quadrupole has a non-zero mean of $5 \%$ of the axial dipole. This variant is most similar to CJ98 in terms of the $E / I$ trends. It is encouraging that for all the models except CP88 and Model B, there is a great deal of concordance in the most critical interval of inclinations steeper than $30^{\circ}$ (inclinations shallower than this suffer less significant flattening because of the tangent relationship with applied field).

Another interesting set of field models to explore are those produced by numerical models which attempt to simulate behavior of the geodynamo. For this purpose, we use two sets of field models from Glatzmaier et al. (1999) that produced reasonable

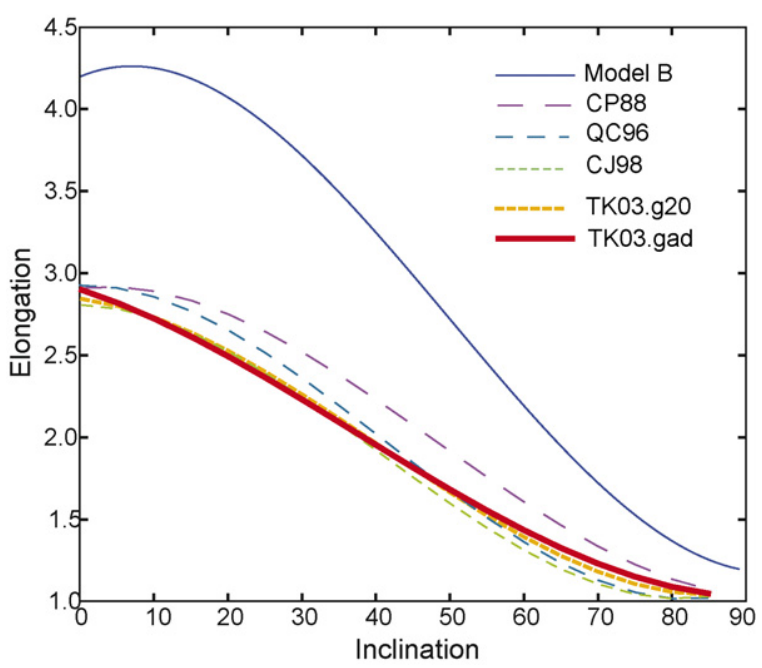

Fig. 2. Elongation/inclination relationship predicted from various paleosecular variation models.

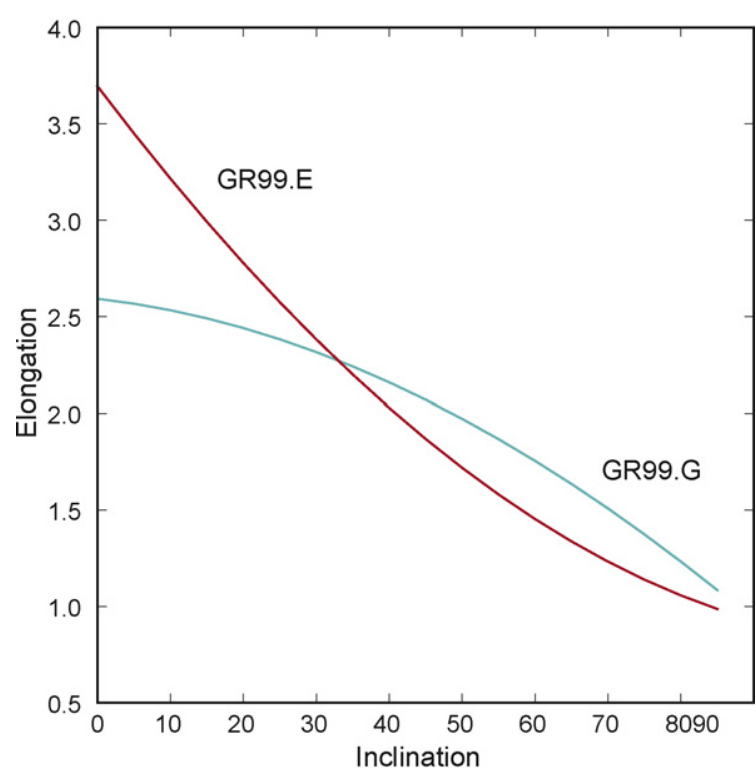

Fig. 3. E/I trends from Glatzmaier et al. (1999), models GR99.E and GR99.G.

end-members for "Earth-like" behavior: the "uniform core mantle boundary heat flux" model (here called GR99.G) shown in Fig. $1 \mathrm{~g}$ and model "GR99.E" shown in Fig. 1e of Glatzmaier et al. (1999). Model GR99.E had no reversals over the 300 kyr interval simulated while model GR99.G had two. Model GR99.E had a higher average dipole moment $\left(58 \mathrm{ZAm}^{2}\right)$ and lower scatter in the VGPs $(S=8.5$ for $\lambda=90)$. Model GR99.G had an average dipole moment of $32.2 \mathrm{ZAm}^{2}$ with a higher polar scatter in the VGPs $(S=13)$, much lower than post-CP88 GGP predictions.

There are 7470 field models from GR99.G and 3596 field models from GR99.E. These were treated in a similar fashion to the PSV models. However, because these models are not zonal, we evaluated the field at six longitudes and at $10^{\circ}$ latitudinal intervals from -80 to $80^{\circ}$. The results from the southern hemisphere were mapped into the northern hemisphere (by taking the negative of the inclination value). In order to keep about the same number of total directions as used in the PSV models, only every 10th field model for GR99.G was used resulting in 8964 directions for model GR99.G at each latitude (except the equator for which there were 4488). Every fifth model for GR99.E was used for a total of 8640 directions for non-equatorial sites from model GR99.E and 4320 for equatorial sites.

The predicted trends of $E / I$ from best fit polynomials for the two numerical simulations are listed in Table 2 and their curves are shown in Fig. 3. Model GR99.E predicts much more elongate distributions for low latitude (inclination) observation sites, consistent with the low degree of scatter in the simulated VGPs, while Model GR99.G predicts less elongate directions at low latitude than the statistical models.

We consider the various statistical PSV models to provide reasonable estimates for predicted $E / I$ trends and take heart from the high degree of consistency between the more recent versions. As the paleosecular variation data sets from lava flows continue to improve (see e.g., Johnson et al., 2008), we can expect that the uncertainty in the $E / I$ method stemming from a poorly constrained target trend will decrease.

\subsection{How large a data set is required to estimate E/I?}

Even if the $E / I$ trends are reasonably well constrained, a given data set must be large enough to allow a meaningful estimate. How large a data set is required for this purpose? To investigate this issue we used a Monte Carlo approach, whereby $N$ directions 

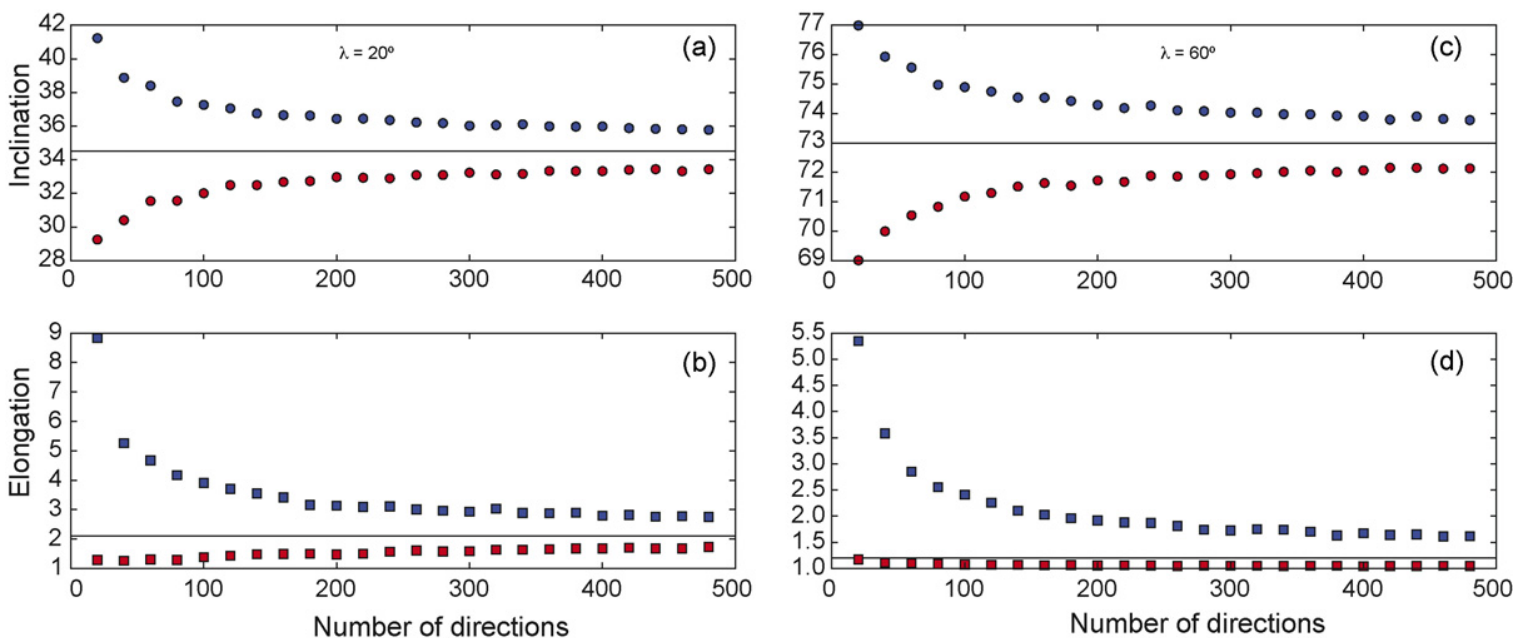

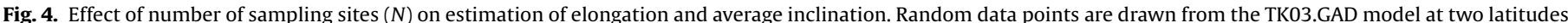

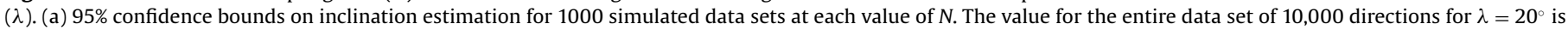
shown as the solid line. (b) Same as (a) but for the elongation estimates. (c) Same as (a) but for $\lambda=60^{\circ}$. (d) Same as (b) but for $\lambda=60^{\circ}$.

were drawn at random from a set of 10,000 directions predicted by the TK03.GAD model at a specified latitude $\lambda$. For each $N$ we drew 1000 such data sets and found the 95\% confidence bounds on $E$ and $I$. $N$ ranged from 20 to 500 simulated sampling sites. In Fig. 4a and b we plot the upper and lower 95\% confidence bounds of the estimated elongations and inclinations, respectively for $\lambda=20^{\circ}$. [Note that the average inclination of $34.6^{\circ}$ underestimates the inclination expected from a GAD field of $36.1^{\circ}$ in the well known effect described by Creer (1983) and Tauxe et al. (2004).] The same experiment for $\lambda=60^{\circ}$ is shown in Fig. 4c and d. For $N<\sim 100-150$, the confidence bounds on $E$ and $I$ are large, limiting our ability to apply the $E / I$ method with any reliability. However, for larger data sets $N>100-150$, the confidence bounds become reasonable and the method can be applied as long as the source of scatter is geomagnetic and sedimentary flattening in origin. It is interesting to note that the confidence bounds on $E$ are asym-

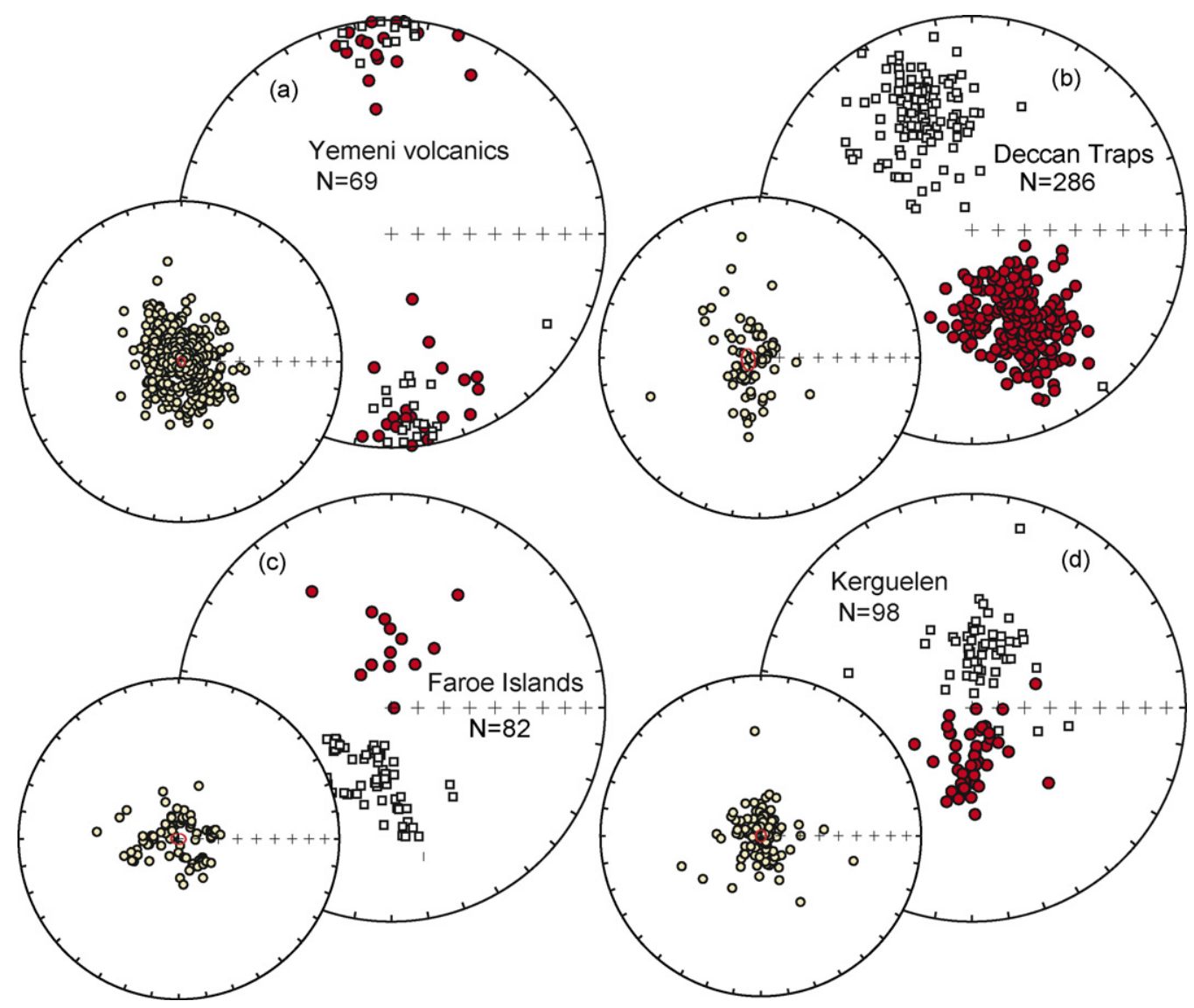

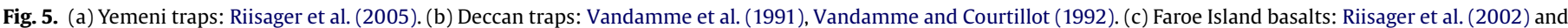
(d) Kerguelen: Plenier et al. (2002). 
Table 3

Summary of Large Igneous Provinces

\begin{tabular}{|c|c|c|c|c|c|c|c|c|c|}
\hline LIP & Lat. & Long. & Age (Ma) & $N$ & $I^{\mathrm{a}}$ & $E^{\mathrm{b}}$ & $\lambda^{\mathrm{c}}$ & $S_{\mathrm{p}}{ }^{\mathrm{d}}$ & Reference \\
\hline Deccan & 23 & 81.5 & $\sim 65$ & 286 & $46.1(44.4-47.9)$ & $1.93(1.56-2.48)$ & 28 & $19.3(18.0-20.3)$ & $\begin{array}{l}\text { Vandamme et al. (1991), } \\
\text { Vandamme and Courtillot } \\
\text { (1992) }\end{array}$ \\
\hline Faroe & 60.5 & -7 & $55-58$ & 82 & $60.9(58.6-63.1)$ & $1.78(1.24-2.90)$ & 42 & $16.9(15.0-18.5)$ & Riisager et al. (2002) \\
\hline Kerguelen & -49 & 69.5 & $24-30$ & 98 & $69.2(67.0-71.4)$ & $1.22(1.06-2.33)$ & 53 & $16.3(13.5-19.3)$ & Plenier et al. (2002) \\
\hline Yemen & 15 & 44 & $28-30$ & 69 & $1.56(0.1-5.7)$ & $2.73(1.48-5.73)$ & 1 & $16(12.8-19.7)$ & Riisager et al. (2005) \\
\hline \multicolumn{10}{|l|}{ Paraná } \\
\hline Intrusives & $-20 /-25$ & $-49 /-51$ & 125 & 190 & $38.6(36.7-40.3)$ & $1.82(1.28-2.75)$ & 21.8 & $14.4(12.8-15.5)$ & $\begin{array}{l}\text { Ernesto et al. (1999), Raposo } \\
\text { and Ernesto (1995) }\end{array}$ \\
\hline Extrusive & $-17 /-29$ & $-55 /-48$ & $132-133$ & 400 & $39.8(38.67-40.9)$ & $1.54(1.26-2.05)$ & 21.8 & $18.6(16.1-20.8)$ & $\begin{array}{l}\text { Alva-Valdivia et al. (2003), } \\
\text { Ernesto et al. (1990, 1999) }\end{array}$ \\
\hline Extrusives ${ }^{\mathrm{e}}$ & $-18 /-29$ & $-55 /-48$ & $132-133$ & 223 & $40.0(38.7-41.4)$ & $1.61(1.22-2.31)$ & 22.8 & $14.4(12.6-15.9)$ & $\begin{array}{l}\text { Alva-Valdivia et al. (2003), } \\
\text { Ernesto et al. (1990, 1999) }\end{array}$ \\
\hline$N$ of $\mathrm{RPL}^{\mathrm{f}}$ & $-18.5 /-25$ & $-48 /-55$ & $125-133$ & 231 & $37.7(36.2-39.3)$ & $1.68(1.23-2.45)$ & 21.1 & $16.8(15.2-18.5)$ & $\begin{array}{l}\text { Ernesto et al. (1990, 1999), } \\
\text { Raposo and Ernesto (1995) }\end{array}$ \\
\hline$S$ of RPL & $-26 /-29$ & $-48 /-55$ & $132-133$ & 359 & $40.5(39.3-41.7)$ & $1.57(1.30-2.16)$ & 23 & $19.7(16.8-21.6)$ & $\begin{array}{l}\text { Alva-Valdivia et al. (2003), } \\
\text { Ernesto et al. (1990, 1999) }\end{array}$ \\
\hline
\end{tabular}

\footnotetext{
a Average inclination plus bootstrapped 95\% confidence bounds.

b Elongation plus bootstrapped 95\% confidence bounds.

c Paleolatitude calculated from average inclination, assuming a GAD field.

d $S$ of Cox (1969) calculated relative to the principal axis of the VGPs and not the spin axis. No VGP cutoff was applied.

e Excluding regions near tectonic lineaments or arches.

f Rio Piquiri Lineament.
}

metric and the lower confidence is quit close to the expected value.

\subsection{Applicability of E/I method through geologic time}

Presently available statistical PSV models are based on data for which we can neglect or constrain plate motion, hence data from the last five million years. Given the dependence of elongation with VGP scatter, particularly at low latitude, it is possible that if the character of secular variation changes (as suggested by for example, McFadden et al., 1991), the $E / I$ trends might also change, hence it is worth exploring the $E / I$ trends through geologic time. In this section we assemble data sets since the early Cretaceous for the purposes of testing the $E / I$ trends through time.

The statistical field models require paleolatitude information because they attempt to match predicted scatter in directions or VGPs with observed latitudinal trends. For testing $E / I$ trends, it is fortunate that we do not require that paleolatitude be known, only that paleohorizontal be known. This is because we calculate average elongation and inclination for the data set. For a GAD field, the inclination can easily be translated into latitude, but that is an unnecessary assumption for testing the $E / I$ trends in the past. What is required is a large number $(\sim 100)$ of spot readings of the ancient geomagnetic field from a particular region spanning a time interval short enough that the continent can be considered stationary ( $i \sim 5$ Myr). Therefore, paleomagnetic studies of large igneous provinces (LIPs) are ideally suited for a test of the applicability of the $E / I$ trend.

Five LIPs have sufficient paleomagnetic data from them to provide a useful check: the Oligocene Kerguelen (Plenier et al., 2002) and Yemeni (Riisager et al., 2005) LIPs, the Paleocene Faroe Island LIP (Riisager et al., 2002), the Cretaceous/Tertiary boundary Deccan Traps (Vandamme et al., 1991; Vandamme and Courtillot, 1992) and the early Cretaceous Paraná Magmatic Province (Ernesto et al., 1990, 1999; Alva-Valdivia et al., 2003; Raposo and Ernesto, 1995). Directions from the first four LIPs are plotted in Fig. 5; see also Table 3. Shown as insets are the data with the antipodes of the reverse directions plotted along with the normal directions after rotation such that the principle direction of the data set is at the center of the diagram. Kent ellipses are plotted as a red circle. The Yemeni and Deccan data show the elongation in the North/South plane char- acteristic of dipolar field directions at low to moderate latitudes while the steeper directions from the Faroe and Kerguelen Islands are more symmetric.

To investigate the E/I behavior in our LIP data, we plot elongation versus average inclination in Fig. 6. To estimate 95\% confidence bounds for the $E / I$ pairs, we employ a bootstrap method whereby each data set is resampled (with replacement) 5000 times and the E/I pair calculated for each bootstrapped data set. The bounds containing $95 \%$ of these estimates are shown as solid horizontal (uncertainty in average inclination) and vertical (uncertainty in elongation) lines. The overall consistency of predicted and observed $E / I$ pairs suggests that inclinations corrected using the $E / I$ method can be used with some confidence.

One requirement for the successful application of the $E / I$ method is that all the scatter be either of geomagnetic in origin or from sedimentary flattening and other sources of scatter can lead to erroneous results. In igneous rocks, there is no sedimentary flattening,

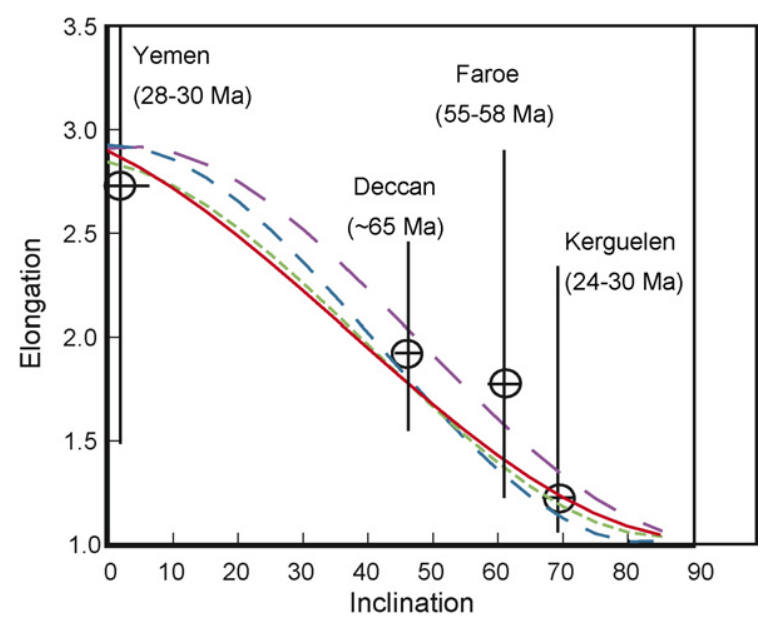

Fig. 6. El plot of data from Fig. 4. Circles are $E / I \mathrm{~s}$ from each data set and the cross bars are the $95 \%$ bootstrapped confidence bounds. Dashed line is E/I relationship from CP88 of Constable and Parker (1988), dotted line is from QC96 of Quidelleur (1996) and solid line is from TK03 of Tauxe et al. (2004). 


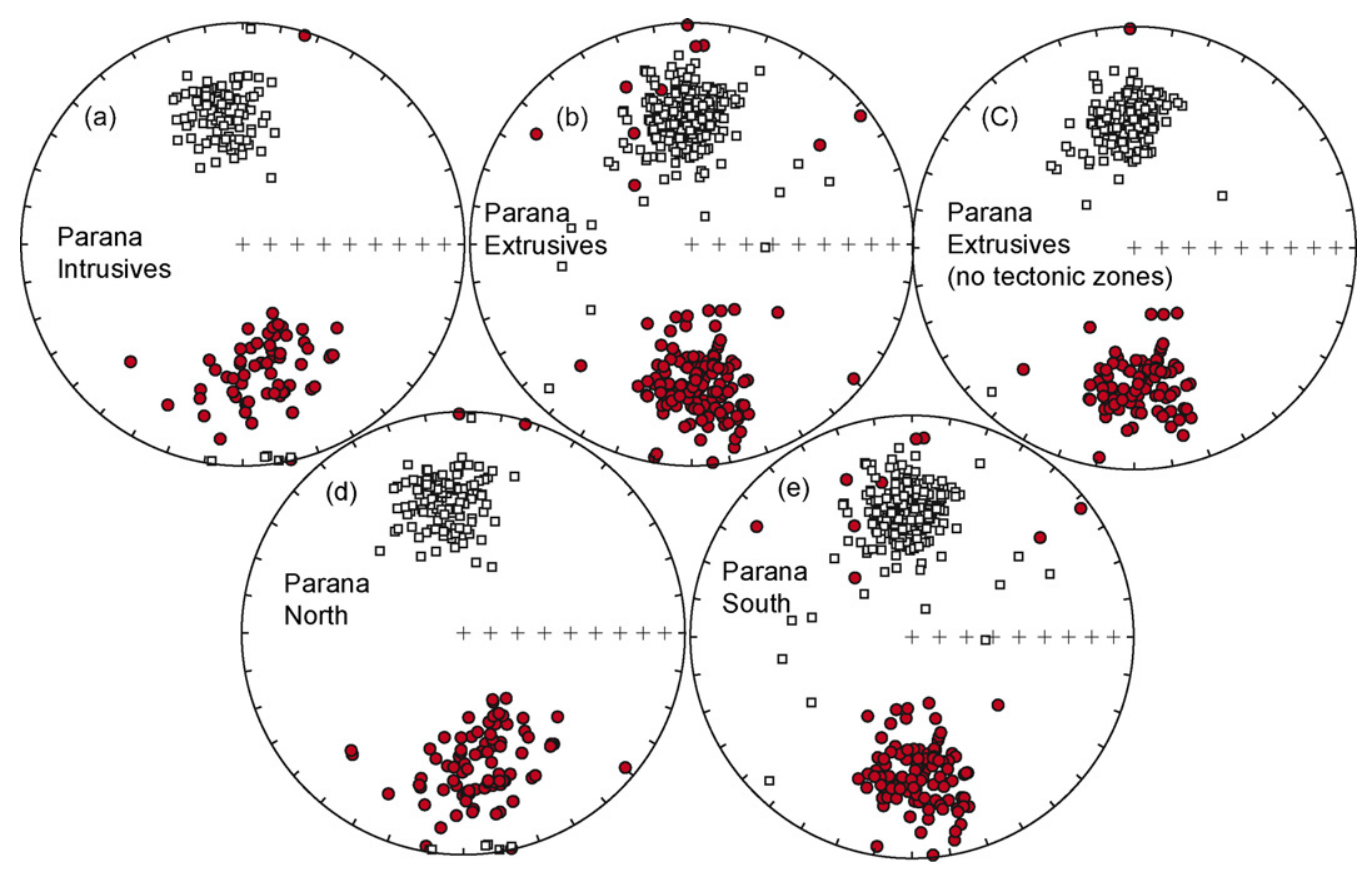

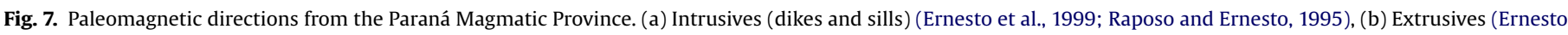

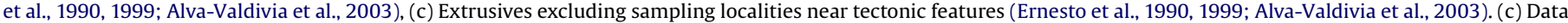
from north of the Rio Piquiri Lineament. (d) Data from south of the Rio Piquiri Lineament.

but unrecognized tectonic tilting or other sources of scatter can play a role. We illustrate the effect of these unwanted sources of scatter by using the The Paraná Magmatic Province (PMP).

The PMP is cut by tectonic 'lineaments' and arch-type structures (Piccirillo et al., 1988) and paleomagnetic data have been published for lava flows, dikes and sills. The dikes and sills are significantly younger than the extrusives (Renne et al., 1996), although the APWP of Besse and Courtillot (2002), for example, predicts about a $2^{\circ}$ difference in direction between the two age groups. Perhaps more important than age span, the PMP also spans a large range in (paleo)latitudes. The directions from the PMP separated by emplacement mechanism, tectonic environment and geographic locations are shown in Fig. 7. When all the data are combined together, the $E / I$ estimate is significantly different from the curve expected from the TK03.GAD model (and all the other PSV models as well). It may be that the early Cretaceous field was different from other times tested. Alternatively it may be that there is a source of scatter other than the geomagnetic field which leads us to an erroneous result.

We treat the PMP data by first examining the intrusive/extrusive data sets separately. These data sets differ not only in what is presumably an unimportant distinction between being flows, dikes or sills (if paleohorizontal is known), but also in geographic and temporal extent. The instrusives are primarily from north the Rio Piquiri Lineament (RPL) and are as young as 120 Ma while the extrusives span the entire PMP (17-29 $\mathrm{S}$ ) and are $132-133 \mathrm{Ma}$ (Renne et al., 1996). Intrusives and extrusive directions are plotted in Fig. 7a and $b$, respectively. Some of the sampling localities of the extrusives are quite close to the tectonic lineaments and arches documented by Piccirillo et al. (1988) and these appear to have most of the highly scattered directions. Therefore, we exclude sites near the following tecontic features in Fig. 7c: The Torres Pousadas lineament (BV, CV, PH, BM and TA of Ernesto et al. (1990)), Rio Iguagu lineament (IC, PA 1-4 of Ernesto et al., 1990 and SC of Alva-Valdivia et al., 2003), Goiania Arch (MG 3 of Ernesto et al. (1990)), Paranapaneme/Guapiara lineament (PP and MI of Ernesto et al., 1990), Camp Grande Arch (MT 6 and 8), Torres Arch (PC) and Bom Jardina de Goias Arch (MG 2). We exclude all the data from the suspect regions, and not just the deviant directions, hence the number of observations is dramatically reduced (see Table 3 ). In Fig. 8 b we plot the E/I calculations for the two extrusive data sets and the intrusive one against the E/I curves expected from TK03.GAD. All of these data sets are compatible with the expected trend but the error bars are quite large.
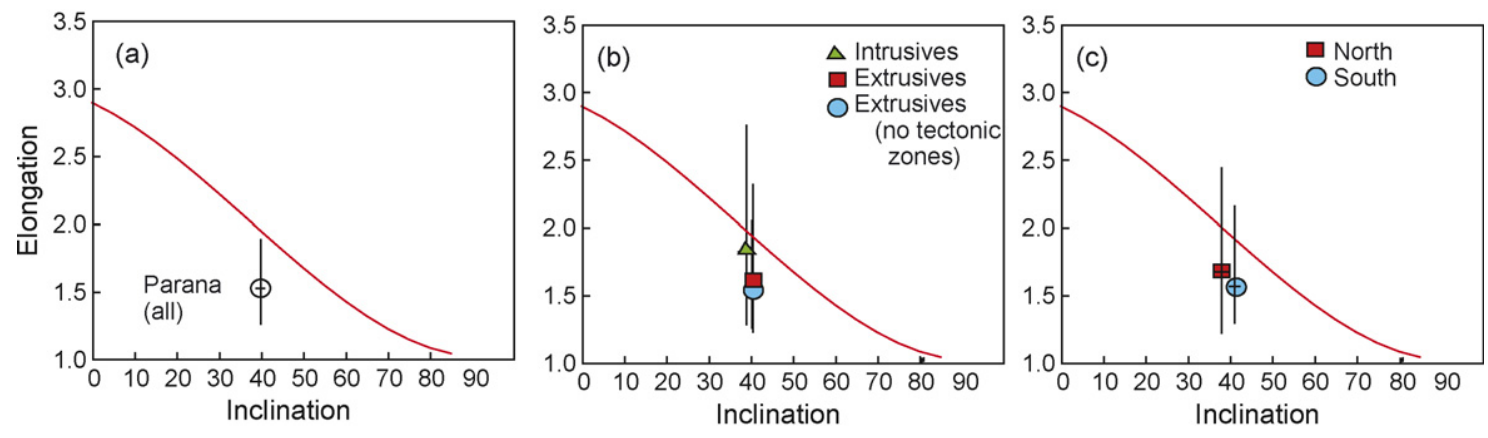

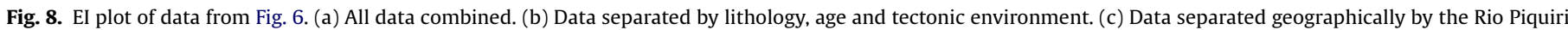
Lineament. 
Because the PMP spans such a large range in (paleo)latitude $>$ $10^{\circ}$, it is likely that combining the data together results in enhanced scatter in the inclination which does not reflect paleosecular variation but the rather uninteresting dependence of inclination on latitude. Therefore, we plot the data from north and south of the RPL in Fig. 7c and d, respectively. The E/I estimates are shown in Fig. 8c. The latitudinal effect is significant-the two data sets clearly have distinct inclinations and the overall fit to the TK03.GAD curve is improved.

\section{Geological implications of E/I corrected data sets}

There are a number of published studies that used the $E / I$ method to detect and correct for sedimentary inclination error to resolve geologic problems. These include the problem of a persistent shallow bias in paleomagnetic directions in Cenozoic sediments from Central Asia (Tauxe et al., 2004) and from the Mediterranean region (Krijgsman and Tauxe, 2004), the extended interval of shallow inclinations that implied very slow poleward motion over the Late Triassic for continents adjacent to the North Atlantic and overlap of Greenland with the North American continent (Kent and Tauxe, 2005), and the so-called "Baja British Columbia" hypothesis (Krijgsman and Tauxe, 2006) suggested by comparatively shallow inclinations in both plutonic and sedimentary rocks. The most recent study using the E/I correction method was an assessment of the reality of the J1 cusp, the long-supposed abrupt change in polar wander for North America at around 200 Ma (Kent and Olsen, 2008).

One of the motivations for the development of the $E / I$ correction method and the basis for its initial test (Tauxe et al., 2004) was the large data set consisting of 222 sites of paleomagnetic directions from mid-Cenozoic redbeds from Central Asia published by Gilder et al. (2001). As commonly found in sedimentary units from Central Asia, the mean inclination $\left(43.7^{\circ}\right)$ is about $20^{\circ}$ too shallow compared to predicted values (in this case, $63^{\circ}$ ) based on reference paleopoles (e.g., apparent polar wander path of Besse and Courtillot, 2002). The initial distribution of directions was elongated E-W, which immediately suggested that the anomalously shallow mean inclination is unlikely to be the result of a geomagnetic field with a significant axial octupolar contribution because that always produces elongation in the N-S plane. Application of the $E / I$ correction technique gave a best-fit inclination of $64^{\circ}(95 \%$ confidence bounds range from $56^{\circ}$ to $69^{\circ}$ ), in excellent agreement with the APWP prediction as well as with regional volcanic data (Gilder et al., 2003). These results virtually rule out a significant role for either axial octupolar fields or major crustal shortening as the cause for the inclination bias observed in the Asian sedimentary rocks and strongly support the sedimentary flattening hypothesis of Gilder et al. (2001, 2003) and Tan et al. (2003).

A second study dealt with the strong bias toward shallow inclinations that had long been noted in paleomagnetic data from the Mediterranean region. The shallow bias had variously been attributed to tectonics, large non-dipole fields, or systematic flattening of the paleomagnetic directions. Krijgsman and Tauxe (2004) applied the $E / I$ correction method to two extensive paleomagnetic datasets published for Miocene sediments from Spain and from Crete that are representative of this pattern of shallow inclinations. After correction, the Spanish data agreed with the expected paleolatitude of the region; the data from Crete suggested it occupied a position several hundred kilometers farther north than would conventionally be predicted, but the implied southward migration of Crete since the late Miocene was in agreement with geodynamical models and the present-day sense of motion from GPS measurements. This study concluded that sedimentary inclination error is the most likely cause of the shallow inclination bias in the
Mediterranean and not persistent non-dipole geomagnetic fields or northward tectonic transport.

Another successful application of the E/I correction technique was on data from the magnetostratigraphically well-correlated continental basins distributed along the margins of the North Atlantic that developed during rifting of the Pangea supercontinent in the early Mesozoic. The paleomagnetic records reveal a significant $10^{\circ}$ foreshortening in recorded Late Triassic paleolatitudes between eastern Greenland (Kent and Clemmensen, 1996) and the basins in eastern North America that had to be about $30^{\circ}$ to the south (Kent and Olsen, 1997; Kent et al., 1995). This discrepancy could again be due to inclination error or large non-dipole contributions to the time-averaged field. E/I analyses of 10 separate sedimentary data sets from these basins brought all the paleolatitude data into mutual agreement (Kent and Tauxe, 2005). Moreover, paleomagnetic data from coeval igneous rock units, which are not subject to inclination error, were now in excellent agreement with the corrected data. Comparing the sedimentary results with the igneous results provided an independent check on the validity of the corrections for inclination error. One of the consequences of the revised paleolatitudes for the Late Triassic was that they indicated a much faster rate of poleward motion $\left(0.6^{\circ} / \mathrm{Myr}\right)$ than was implied by the original uncorrected data. The uncorrected data were biased by inclination error and underestimated paleolatitudinal change. The distribution of climate-sensitive facies could thus be better understood in terms of the drift of the continent(s) across zonal climate gradients.

As much as any tectonic scenario, the Baja British Columbia hypothesis for terrane motions in the North American Cordillera is based on observations that paleolatitudes (inclinations) for outboard terranes are invariably much lower (shallower) than would be predicted from the North American APWP if the terranes were fixed to North America. E/I analysis (Krijgsman and Tauxe, 2006) of published paleomagnetic data from two key Cretaceous sedimentary units in the Insular Superterrane showed that continental sediments of the Silverquick formation were not seriously affected by inclination error because the magnetization was likely to be a secondary chemical remanence, whereas marine sediments of the Nanaimo Group were affected by about $9^{\circ}$ of flattening, in agreement with corrections by the anisotropy method (Kim and Kodama, 2004) but insufficient to account entirely for the anomalously shallow inclinations.

Finally, a recent study of Early Jurassic continental sediments interbedded with and overlying basalt units of the Central Atlantic Magmatic Province in the Hartford basin confirmed that the characteristic magnetizations of the hematitic sediments were significantly shallower than those of the CAMP volcanics, providing prima facie suspicion of inclination error, but came into close agreement after $E / I$ corrections (Kent and Olsen, 2008). The mean $201 \mathrm{Ma}$ paleopole based on corrected sedimentary data (that are supported by corrections using the anisotropy method; Tan et al., 2007) and CAMP volcanics pole (Prévot and McWilliams, 1989) from the Hartford and Newark basins do not agree with the J1 cusp, for which a simpler (better) interpretation is as an artifact of sedimentary inclination error and rotation of the Colorado Plateau.

\section{Direct comparisons of $E / I$ and remanence anisotropy correction techniques}

Currently, two independent techniques have been developed to check and correct for sedimentary inclination flattening: the justdiscussed $E / I$ technique and the remanence anisotropy method. The remanence anisotropy correction technique was initially proposed by Jackson et al. (1991) and has been successfully applied in many studies (e.g., Kodama, 1997; Kodama and Davi, 1995; Tan 
and Kodama, 1998, 2002; Tan et al., 2003, 2007; Vaughn et al., 2005). This approach relies on the measurement of the magnetic anisotropy of a specimen and the magnetic anisotropy of the individual magnetic particles in the specimen. Following Jackson et al. (1991), these parameters may be used to correct the inclination of an individual specimen. The anisotropy tensor inclination correction uses the remanence anisotropy, not the anisotropy of magnetic susceptibility, of the magnetic grains that carry the characteristic remanence of the specimen. For magnetite-bearing rocks, partial anhysteretic remanent magnetizations (pARMs) are applied in nine different orientations to determine the anisotropy of anhysteretic remanence (AAR). For hematite-bearing rocks, partial thermal demagnetization of an isothermal remanent magnetization (IRM) applied in nine different orientations is used to measure the anisotropy of isothermal remanence (AIR) of the high unblocking temperature magnetic grains carrying the characteristic remanence (Tan and Kodama, 2002). A modified AIR approach can be used to avoid the effects of high temperature heating. In this modification, high fields (2-5T) are used to totally reset the IRM for each of the nine orientations, thus eliminating the need for high temperature demagnetization to remove the IRM from the previous orientation (Kodama and Dekkers, 2004; Billardello and Kodama, 2007). To complement the AIR technique, the inclination can also be corrected with the anisotropy of magnetic susceptibility (AMS) that is removed during the chemical demagnetization steps that are used to isolate the characteristic remanence of a specimen (Tan et al., 2003). The anisotropy-based inclination correction technique also depends on knowing the individual particle anisotropy of the magnetic grains. The individual particle anisotropy is best determined either through redeposition of magnetic extracts in DC magnetic fields ( $50 \mathrm{mT}$ for magnetite; $150 \mathrm{mT}$ for hematite) or by laboratory compaction experiments with reconstituted sediments made from the sedimentary rock being studied. A third method used to determine the individual particle anisotropy, fitting corrected inclinations to theoretically predicted flattening behavior, has been shown to be successful in a study for which the curve fitting approach and direct measurement of a magnetic extract were compared (Billardello and Kodama, 2007), but theoretical curve fitting has been called into question (de Groot et al., 2007) by a numerical modeling study.

The two inclination flattening detection/correction methods have different advantages and shortcomings. The anisotropy tensor correction method involves extrapolation from the analysis of a subset, typically small, of the total specimens in a paleomagnetic study and is critically dependent on the empirical determination of the individual magnetic particle anisotropy. The E/I method requires a large number of specimens that are assumed to have the same average flattening factor and relies on an assumed paleosecular variation geomagnetic field model. Because the two methods are based on entirely different assumptions, a comparison of the corrected inclinations obtained by the different techniques on the same sedimentary sequence serves as a test of both methods. There are two such tests available from the published literature: the late Triassic/early Jurassic red sedimentary rocks of Newark Basin in which the remanence is carried by hematite (Kent and Tauxe, 2005; Tan et al., 2007) and the titanohematite-bearing Paleocene sedimentary rocks from the Nacimiento Formation of New Mexico (Butler and Taylor, 1978; Kodama, 1997).

In the Newark Basin study, Tan et al. (2007) measured the remanence anisotropy of 19 red bed specimens from the Passaic Formation in northern New Jersey, USA. Remanence anisotropy of the ChRM-carrying grains was determined by application of a saturation IRM in nine orientations with intermediate high temperature thermal demagnetization $\left(600^{\circ} \mathrm{C}\right)$ to remove the IRM of the low unblocking temperature hematitic red pigment and
Table 4

Comparison of $E / I$ and remanence anisotropy correction methods

\begin{tabular}{lllll}
\hline Data Set & $I_{\exp }$ & $I_{\mathrm{obs}}$ & $I_{\mathrm{aar}}$ & $I_{\mathrm{ei}}$ \\
\hline Martinsville & & 18.2 & 29.1 & $36.9(31.7-41.9)$ \\
Weston & & 17.5 & 28.1 & $34.9(29.6-39.8)$ \\
Upper Passaic & $36.4^{\mathrm{a}}$ & 18.1 & 28 & $36.4(32.5-39.9)$ \\
Upper Passaic-N & $36.4^{\mathrm{a}}$ & 22.3 & & $30.0(25.8-33.9)$ \\
Upper Passaic-R & $36.4^{\mathrm{a}}$ & 13.8 & & $37.1(31.8-42.3)$ \\
Nacimiento & $60.3^{\mathrm{b}}$ & 51.2 & $56.9-57.7$ & $56.1(50.8-68.2)$ \\
\hline
\end{tabular}

a Expected inclination from the Hartford/Newark volcanics pole of Prévot and McWilliams (1989).

b Expected inclination from Besse and Courtillot (2002).

then high temperature thermal demagnetization $\left(690^{\circ} \mathrm{C}\right)$ to totally remove the saturation IRM between orientations. The chemical demagnetization-AMS approach to remanence measurement did not prove successful for these rocks. The resulting AIR fabric, with minimum principal axes perpendicular to bedding, is consistent with the high temperature characteristic remanence (ChRM) being carried by a hematite detrital remanence (DRM) or an early crystallization remanence (CRM) that has subsequently been affected by compaction. The individual particle anisotropy for the Passaic Formation red bed specimens was estimated from the individual particle anisotropy derived from the Cretaceous Kapusaliang Formation of western China (Tan et al., 2003) by curve fitting and from the measurement of redeposited, oriented specular hematite flakes broken from a large hematite grain. Tan et al. (2007) applied their anisotropy correction to the results of Kent et al. (1995) for the Martinsville and Weston deep cores from the Newark Basin Coring Project (NBCP) because the ChRMs and the demagnetization behavior they observed from their small number of Passaic Formation specimens agreed with the results from these deep cores. The average inclination for the Martinsville and Weston cores was steepened by $10-11^{\circ}$ by the anisotropy correction (see Table 4 ). The Martinsville core mean inclination was corrected from $18.2^{\circ}$ to $29.1^{\circ}$ and the Weston core inclination was corrected from $17.5^{\circ}$ to $28.1^{\circ}$.

By comparison, when the $E / I$ technique was applied to the Martinsville and Weston core inclinations, as part of a larger inclination correction study of Late Triassic paleolatitudes for Atlantic-bordering continents (Kent and Tauxe, 2005), the inclinations were steepened by $16^{\circ}$ (Martinsville $18.2^{\circ}$ to $34.9^{\circ}$ and Weston $17.5^{\circ}$ to $33^{\circ}$ ). (Repeating the analysis using the revised parameters yields corrected inclinations of $36.9_{31.7}^{41.9}$ and $34.9_{29.6}^{39.8}$ for the Martinsville and Weston cores, respectively; see Table 4.)

The $200 \mathrm{Ma}$ pole for North America from the globally synthetic apparent polar wander path of Besse and Courtillot (2002) of $69.8^{\circ} \mathrm{N} / 95.6^{\circ} \mathrm{E}$ (based in part on the CAMP igneous result) yields an expected inclination of $36.3^{\circ}$ for the Martinsville/Weston core location $\left(40.2^{\circ} \mathrm{N} / 74.6^{\circ} \mathrm{W}\right)$. The pole from volcanic rocks of the Hartford and Newark Basins of Prévot and McWilliams (1989) $\left(68^{\circ} \mathrm{N} / 88.6^{\circ} \mathrm{E}\right)$ gives an expected inclination of $36.4^{\circ}$, virtually identical to that predicted by the Besse and Courtillot (2002) pole. Both of these estimates are somewhat steeper than those of the anisotropy corrected inclinations.

In order to compare the directions expected from the Hartford/Newark basin volcanics, which are from the upper Passaic formation and span the age range of the Martinsville and Weston cores, we combine the data from the two cores to ensure a proper temporal comparison and repeat the $E / I$ procedure. The combined data set is shown in Fig. 9a. The results from the $E / I$ method on the combined data set are shown in Fig. 10. The mean "upper Passaic" inclination is $18.1^{\circ}$ and it corrects to $36.4_{32.5}^{39.9}$ (see also Table 4 ). This result is in excellent agreement with the volcanic data. A close look 


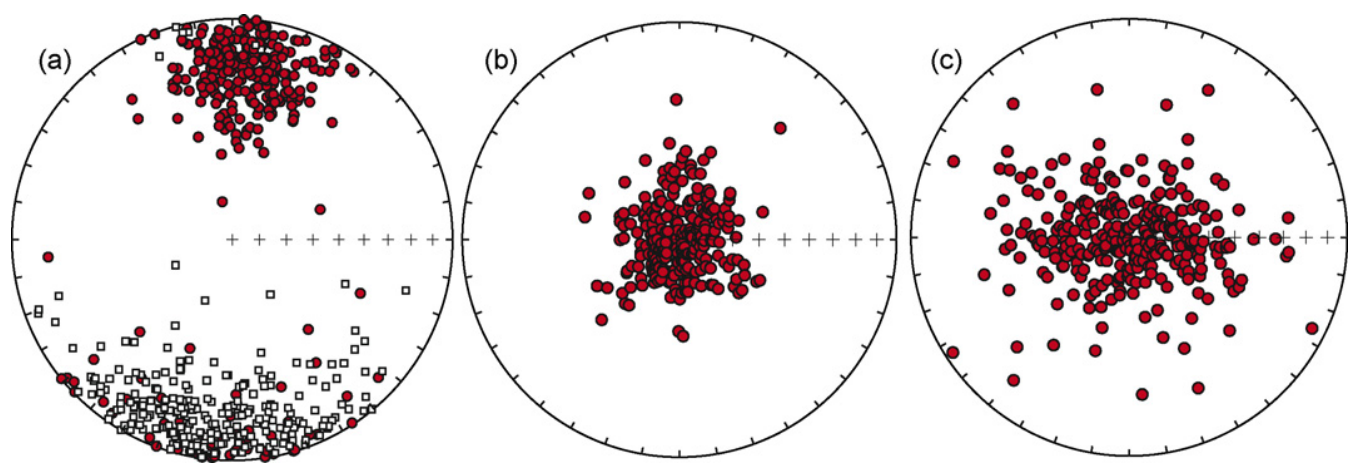

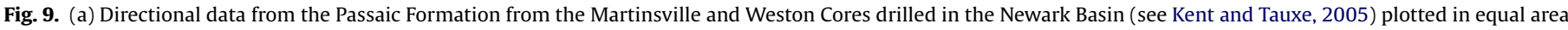
projection. (b) Normal data from (a) transformed to the principal direction. (c) Reverse data from (a) transformed to the principal directions.

at the data, however, reveals that there is a substantial difference between the normal and reverse data sets. We transformed these each to the principal directions (as before) and show the normal and reverse directions in Fig. 9b and c, respectively. While the reverse data set shows the E-W elongation characteristic of sedimentary flattening, the normal data set does not. When performing the $E / I$ method on the two populations separately (see Table 4) we find that the inclination corrects to $30_{25.8}^{33.9}$ for the normal mode and $37.1_{31.8}^{42.3}$ for the reverse mode.

While the uncertainties for the normal and reverse corrected inclination estimates overlap at the $95 \%$ confidence level, it is worthwhile exploring the underlying causes of the different distributions evident in Fig. 9. These data were severely overprinted and it was only with careful thermal demagnetization that the characteristic directions could be identified. It may be that the characteristic directions for the normal data, which were more parallel to the overprint direction, were more difficult to isolate. In this case, there would be a source of directional scatter other than geomagnetic or sedimentary flattening. It is maybe fortuitous that the combined data set agrees so closely with inclination of the Upper Passaic volcanic rocks. Alternatively, bias from overprints works differently on normal and reverse directions and perhaps the two effects cancel out when the data sets are combined.
While the larger corrections for the $E / I$ technique are in agreement, within error limits, with those of the remanence anisotropy technique, Tan et al. (2007) noted the difference between the anisotropy and the E/I correction for the Martinsville and Weston cores and attributed it to errors in the orientation of the NBCP deep cores using the declination of the prominent magnetic overprint in the rocks because orientation errors could cause an overestimate of the E-W elongation of the magnetic directions from the core and hence an overcorrection of inclination. Given the better fit of the combined $E / I$ correction with the expected directions based on the synthetic pole of Besse and Courtillot (2002), as well as CAMP igneous rocks, it appears more likely that the anisotropy approach somewhat undercorrects the upper Passaic Formation red beds. Two reasons for the under-correction could be that it is inappropriate to apply particle anisotropies from the Cretaceous age red beds of China to Triassic red beds of the Newark basin and that only 19 specimens were used for the Newark basin correction and they were all of reverse polarity.

In the anisotropy correction of the Paleocene Nacimiento Formation, Kodama (1997) measured the remanence anisotropy of the ChRM-carrying grain assemblages using partial ARMs (AAR) with standard alternating field demagnetization between the nine orientations because the magnetization is carried by low coer-
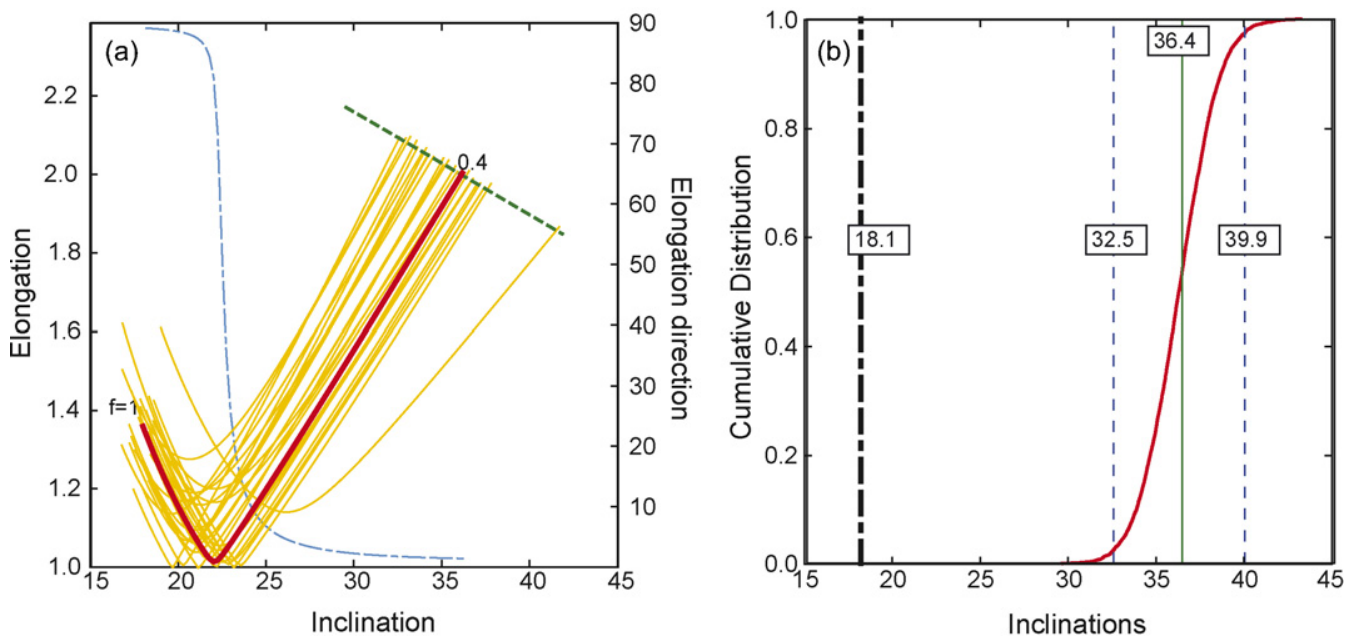

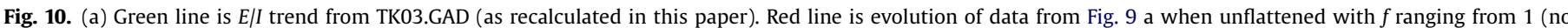

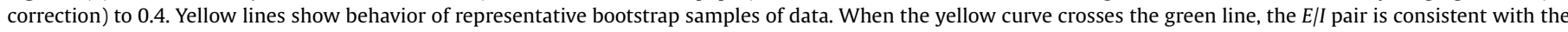

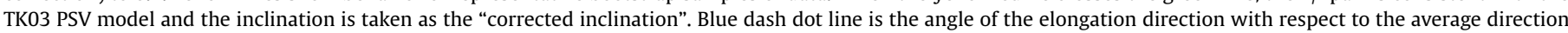

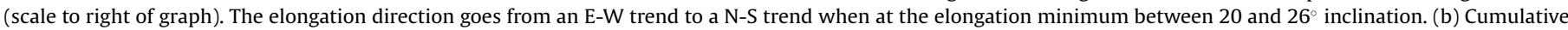

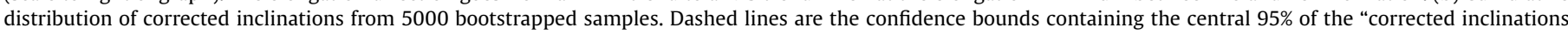

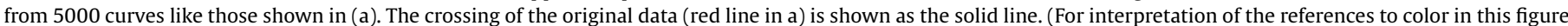
legend, the reader is referred to the web version of the article.) 

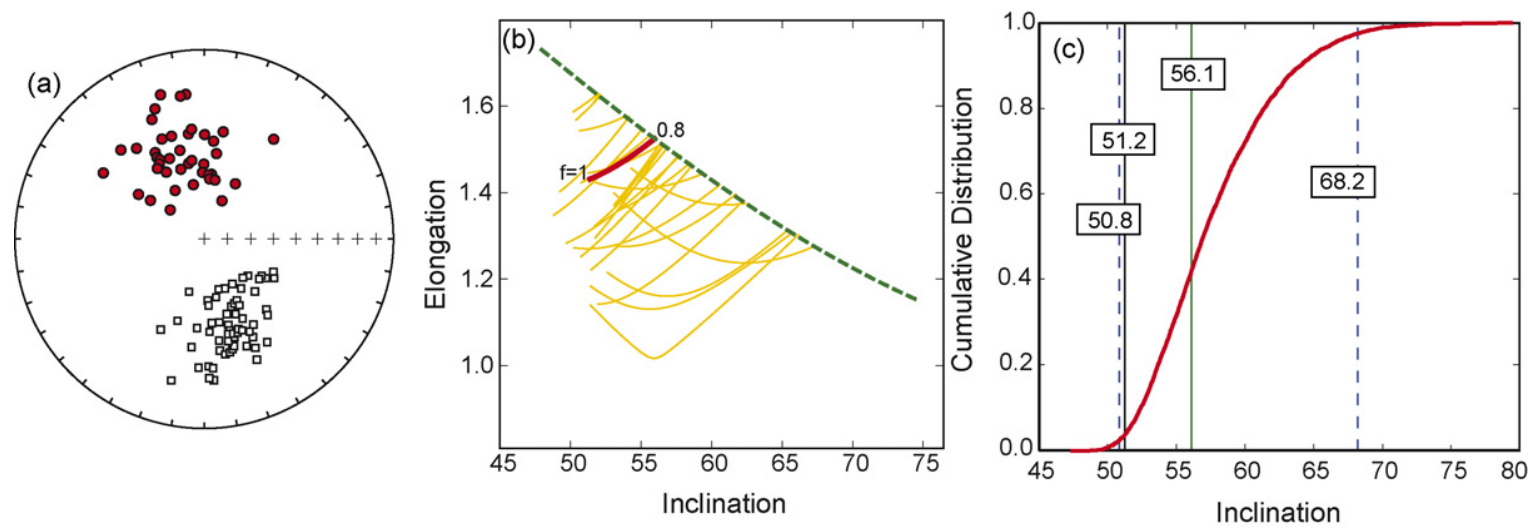

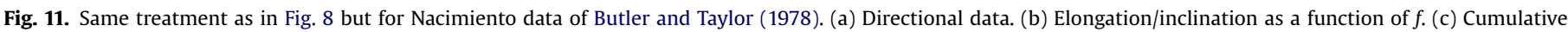
distribution of corrected inclinations from 5000 bootstrapped samples.

civity, ferrimagnetic titano-hematite $(0.45<x<0.60)$. Extensive rock magnetic tests by Butler and Lindsay (1985) have documented this magnetic mineralogy and support the interpretation that the grains are detrital in origin. The development of a magnetostratigraphy for the Nacimiento Formation (Butler and Taylor, 1978) further supports the primary nature of the magnetic minerals. Using an AAR to measure the remanence anisotropy of the Nacimiento Formation avoids the magnetic mineral changes that can be caused by high temperature heating used between orientations for the AIR applied to hematite-bearing sedimentary rocks. Kodama (1997) was able to measure the individual particle anisotropy directly, and independently, by two different techniques and obtained comparable results. He extracted the magnetic minerals from the Nacimiento sedimentary rocks and redeposited the magnetic grains in $\sim 50 \mathrm{mT} \mathrm{dc}$ magnetic fields. This yielded a magnetic particle anisotropy of 2.77. Kodama (1997) was also able to re-compact reconstituted sediment made from Nacimiento material in the laboratory. Measurement of the remanence anisotropy of the laboratory-compacted specimens, for which the inclination shallowing is measured directly, allowed calculation of the independent particle anisotropy, and gave a value of 2.37. The AARs measured for the Nacimiento specimens had magnetic fabrics consistent with DRMs or DRMs subsequently affected by compaction with minimum principal axes perpendicular to bedding. When the Nacimiento Formation ChRMs were corrected by the anisotropy tensor technique, the mean inclination steepened by $\sim 8^{\circ}$. For the particle anisotropy of 2.77 , derived from extracted magnetic grains, the inclination steepened from $49.2^{\circ}$ to $56.9^{\circ}$. For the particle anisotropy of 2.37 , calculated from laboratory compaction experiments, the inclination steepened to $57.7^{\circ}$. In both cases, the $\alpha_{95}$ confidence limit was $\sim 7^{\circ}$. The expected Paleocene $(\sim 57 \mathrm{Ma})$ inclination for the Nacimiento Formation $\left(36.55^{\circ} \mathrm{N} / 107.9^{\circ} \mathrm{W}\right)$, based on the synthetic $60 \mathrm{Ma}$ paleomagnetic pole of Besse and Courtillot (2002), $60.3^{\circ}$, is in reasonable agreement with the anisotropycorrected Nacimiento inclination (see Table 4).

For comparison, we have applied the $E / I$ technique to the Butler and Taylor (1978) 102 site means from the Nacimiento Formation (see Fig. 11a). The corrected inclination is $56.1^{\circ}$. The cumulative distribution of corrected inclinations from 5000 bootstrapped specimens is shown in Fig. 11b with a lower bound of $50.8^{\circ}$ and an upper bound of $68.2^{\circ}$. The $E / I$ technique yields a remarkably consistent result with the anisotropy technique with a statistically insignificantly difference of less than a degree. However, the original inclination of $51.2^{\circ}$ is just inside the $95 \%$ confidence bounds for the corrected inclination.

The $E / I$ and anisotropy tensor inclination detection/correction methods give good independent confirmation of the presence and magnitude of inclination shallowing in sedimentary rocks. In the two tests documented here, the mean $E / I$ correction is nearly identical to the anisotropy-based correction in one case and more in the other, although consistent within the 95\% confidence limits. The main advantage of the $E / I$ technique is that it can be applied directly to standard paleomagnetic data sets, without the need for specialized anisotropy measurements, provided, of course, that the data sets are large enough ( $\sim 100$ sites). It may be the most universal way to document the presence of inclination shallowing. The anisotropy technique, although it requires additional detailed rock magnetic analyses than typical for a standard paleomagnetic study, provides an independent assessment of the inclination corrections obtained by the $E / I$ technique based on an entirely different set of assumptions.

\section{Conclusions}

(1) While there are substantial differences among the statistical (Giant Gaussian Process) paleosecular variation models, all predict distributions of directions that are circular at the poles where the average directions are near vertical and elongate in the meridian near the equator where the directions are near horizontal. This is also true for the numerical dynamo models of, e.g., Glatzmaier et al. (1999). Elongation (defined as the ratio of the intermediate and minimum eigenvalues of the orientation matrix of the directions) ranges from 2.5 to 3 (and even higher for the very tightly grouped VGPs in one of the dynamo models) and trends to unity as the directions become more vertical. In all cases, elongation is perpendicular to meridian. Moreover, there is a smooth trend of elongation versus inclination, allowing a given data set to be tested against the distribution predicted by a given field model.

(2) Elongation produced by sedimentary flattening is elongate in the horizontal plane, hence elongation perpendicular to meridian is intrinsically suggestive of inclination flattening.

(3) Correction for inclination flattening by "unflattening" the directions using progressively smaller flattening factors in the sedimentary flattening formula of King (1955) and comparing the distribution of corrected inclinations with the E/I trends predicted by various field models differ by only $\sim \pm 10 \%$. In all cases tested so far, use of the TK03 model trend yields corrected inclinations in excellent agreement with those of associated lava flows (not subject to flattening).

(4) Available data from LIPs spanning the last 65 Myr are consistent with the E/I trends predicted by PSV models, suggesting that the $E / I$ method can be used to correct sedimentary data for at least the Cenozoic. The success of the $E / I$ technique in cor- 
recting Late Triassic and Early Jurassic sedimentary rocks from the circum-Atlantic region and the resulting agreement with paleomagnetic directions from coeval igneous rocks is an indication that the PSV models may be valid back around $230 \mathrm{Ma}$ or over most of the Mesozoic.

(5) Direct comparison of directions corrected using the $E / I$ method with those corrected using the anisotropy of remenance method of Jackson et al. (1991) (as modified by Kodama and colleagues, e.g., Tan et al. (2007)) yielded consistent results within error.

(6) Further testing of the PSV model predictions will require additional data. In particular, lavas with low mean inclination $\left(0-40^{\circ}\right)$ where elongation is largest and sensitivity to field model(s) greatest would be helpful as would data from lavas from more ancient times.

\section{Acknowledgements}

We would like to thank Gary Glatzmaier for access to field models produced by the numerical magnetohydrodynamic models of Glatzmaier et al. (1999). The manuscript was significantly improved by comments from Cornelis Langereis, Stuart Gilder and the guest editor, Pan Yongxing. This work was partially supported by NSF grant ANT 0538392 to LT. LDEO contribution \#7174.

\section{References}

Alva-Valdivia, L.M., Goguitchaichvili, A., Urrutia-Fucugauchi, J., Riisager, J., Riisager, P., Lopes, O., 2003. Paleomagnetic poles and paleosecular variation of basalts from Paraná Magmatic Province, Brazil: geomagnetic and geodynamic implications. Phys. Earth Planet. Int. 138, 183-196.

Beck, M., 1999. On the shape of paleomagnetic data sets. J. Geophys. Res. 104, 25427-25441.

Besse, J., Courtillot, V., 2002. Apparent and true polar wander and the geometry of the geomagnetic field over the last 200 Myr. J. Geophys. Res. 107, doi:10.1029/2000JB000050.

Billardello, D., Kodama, K., 2007. Direct measurement of hematite individual particle anisotropy: implications for inclination shallowing in red bed DRMs. Eos Trans. AGU Fall Meet. Suppl. 88, GP34A-01.

Bingham, C., 1964. Distributions on the sphere and on the projective plane. Ph.D. Thesis. Yale University.

Bressler, S.C., Elston, D.P., 1980. Declination and inclination errors in experimentally deposited specularite-bearing sand. Earth Planet. Sci. Lett. 48, 227-232.

Butler, R.F., Lindsay, E.H., 1985. Mineralogy of magnetic minerals and revised magnetic polarity stratigraphy of continental sediments, San Jaun Basin, New Mexico. J. Geol. 93, 535-554

Butler, R.F., Taylor, L., 1978. A middle Paleocene paleomagneitc pole from the Nacimiento Formation, San Juan Basin, New Mexico. Geology 6, 495-498.

Constable, C., Johnson, C., 1999. Anisotropic paleosecular variation models: implications for geomagnetic field observables. Phys. Earth Planet. Int. 115, 35-51.

Constable, C., Parker, R.L., 1988. Statistics of the geomagnetic secular variation for the past 5 m.y. J. Geophys. Res. 93, 11569-11581.

Cox, A., 1969. Research note: confidence limits for the precision parameter, K. Geophys. J. R. Astron. Soc. 17, 545-549.

Creer, K., 1962. The dispersion of the geomagnetic field due to secular variation and its determination for remote times from paleomagnetic data. J. Geophys. Res. 67, 3461-3476.

Creer, K., Irving, E., Nairn, 1959. Paleomagnetism of the Great Whin Sill. Geophys. J. Int. 2, 306-323.

Creer, K.M., 1983. Computer synthesis of geomagnetic paleosecular variations. Nature 304, 695-699.

de Groot, L., Haldan, M., Langereis, C., 2007. Inclination correction in red beds. Is it possible? EOS Trans. AGU Fall Meet. Suppl. 88, GP34A-03.

Ernesto, M., Pacca, I., Hiodo, F., Nardy, A., 1990. Palaeomagnetism of the Mesozoic Serra Geral Formation, Southern Brazil. Phys. Earth Planet. Int. 64, 153Zoic 175.

Ernesto, M., Raposo, M.I.B., Marques, L., Renne, P., Diogo, L., de Min, A., 1999. Paleomagnetism, geochemistry and ${ }^{40} \mathrm{Ar} /{ }^{39} \mathrm{Ar}$ dating of the North-eastern Paraná Magmatic Province: tectonic implications. J. Geodyn. 28, 321-340.

Fisher, R.A., 1953. Dispersion on a sphere. Proc. R. Soc. Lond. A 217, 295-305.

Gilbert, W., 1600. On the Magnet, Facsimile of 1900 translation by Silvanus P. Thompson and the Gilbert Club. The Collector's Series in Science. Basic Books, Inc., New York.

Gilder, S., Chen, Y., Cogne, J.-P., Tan, X., Courtillot, V., Sun, D., Li, Y., 2003. Paleomagnetism of Upper Jurassic to Lower Cretaceous volcanic and sedimentary rocks from the western Tarim Basin and implications for inclination shallowing and absolute dating of the M-0 (ISEA?) chron. Earth Planet. Sci. Lett. 206 (3-4), 587-600.

Gilder, S., Chen, Y., Sen, S., 2001. Oligo-Miocene magnetostratigarphy and rock magnetism of the Xishuigou section, Subei (Gansu Province, western China) and implications for shallow inclinations in central Asia. J. Geophys. Res. 106, 30,505-30,521.

Glatzmaier, G.A., Coe, R.S., Hongre, L., Roberts, P.H., 1999. The role of the Earth's mantle in controlling the frequency of geomagnetic reversals. Nature 401 (6756), $885-890$.

Irving, E., 1960. Paleomagnetic directions adn pole positions, 2. Geophys. J. 4, 444-449.

Irving, E., Ward, M., 1963. A statistical model of the geomagnetic field. Pure Appl. Geophys. 57, 47-52.

Jackson, M.J., Banerjee, S.K., Marvin, J.A., Lu, R., Gruber, W., 1991. Detrital remanence, inclination errors and anhysteretic remanence anisotropy: quantitative model and experimental results. Geophys. J. Int. 104, 95-103.

Johnson, C.L., Constable, C.G., Tauxe, L., Barendregt, R., Brown, L., Coe, R., Layer, P., Mejia, V., Opdyke, N., Singer, B., Staudigel, H., Stone, D., 2008. Recent Investigations of the 0-5 Ma geomagnetic field recorded in lava flows. Geochem. Geophys. Geosyst. 9, Q04032, doi:10.1029/2007GC001696.

Kent, D.V., Clemmensen, L., 1996. Paleomagnetism and cycle stratigraphy of the Triassic Fleming Fjord and Gipsdalen Formations of East Greenland. Bull. Geol. Soc. Denmark 42, 121-136.

Kent, D.V., Olsen, P.E., 1997. Paleomagnetism of Upper Triassic continental sedimentary rocks from the Dan River-Danville rift basin (eastern North America). Geol. Soc. Am. Bull. 109, 366-377.

Kent, D.V., Olsen, P.E., 2008. Early Jurassic magnetostratigraphy and paleolatitudes from the Hartford continental rift basin (eastern North America): testing for polarity bias and abrupt polar wander in association with the Central Atlantic Magmatic Province. J. Geophys. Res., 113, B06105, doi:10.1029/2007JB005407.

Kent, D.V., Olsen, P.E., Witte, W.K., 1995. Late Triassic-earliest Jurassic geomagnetic polarity sequence and paleolatitudes from drill cores in the Newark rift basin, eastern North America. J. Geophys. Res. 100, 14965-14998.

Kent, D.V., Tauxe, L., 2005. Corrected Late Triassic latitudes for continents adjacent to the North Atlantic. Science 307, 240-244.

Kent, J.T., 1982. The Fisher-Bingham distribution on the sphere. J. R. Stat. Soc. B. 44 71-80.

Khokhlov, A., Hulot, G., Bouligand, C., 2006. Testing statistical paleomagnetic field models against directional data affected by measurement errors. Geophys. J. Int. $167,635-648$.

Khokhlov, A., Hulot, G., Carlut, J., 2001. Towards a self-consistent approach to palaeomagnetic field modelling. Geophys. J. Int. 145, 157-171.

Kim, B., Kodama, K.P., 2004. A compaction correction for paleomagnetism of the Nanaimo Group sedimentary rocks: implications for the Baja British Columbia hypothesis. J. Geophys. Res. 109, 02102, doi:10.1029/2003JB002696.

King, R.F., 1955. The remanent magnetism of artificially deposited sediments. Mon. Nat. R. Astr. Soc. Geophys. Suppl. 7, 115-134

Kodama, K., 1997. A successful rock magnetic technique for correcting paleomagnetic inclination shallowing: case study of the Nacimiento Formation, New Mexico, USA. J. Geophys. Res. 102, 5193-5205.

Kodama, K., Dekkers, M., 2004. Magnetic anisotropy as an aid to identifying CRM and DRM in red sedimentary rocks. Stud. Geophys. Geod. 48, 747-766.

Kodama, K.P., Davi, J.M., 1995. A compaction correction for the paleomagnetism of the Cretaceous Pigeon Point formation of California. Tectonics 14, 1153-1164.

Krijgsman, W., Tauxe, L., 2004. Shallow bias in Mediterranean paleomagnetic directions caused by inclination error. Earth Planet. Sci. Lett. 222, 685-695.

Krijgsman, W., Tauxe, L., 2006. E/I corrected paleolatitudes for the sedimentary rocks of the Baja British Columbia hypothesis. Earth Planet. Sci. Lett. 242, 205-216.

Lovlie, R., Torsvik, T., 1984. Magnetic remanence and fabric properties of laboratory deposited hematite-bearing red sandstone. Geophys. Res. Lett. 11, 229232.

McElhinny, M.W., McFadden, P.L., 1997. Palaeosecular variation over the past $5 \mathrm{Myr}$ based on a new generalized database. Geophys. J. Int. 131 (2), 240-252.

McElhinny, M.W., Merrill, R.T., 1975. Geomagnetic secular variation over the past 5 m.y. Rev. Geophys. Space Phys. 13, 687-708.

McFadden, P., Merrill, R., McElhinny, M., Lee, S., 1991. Reversals of the Earth's magnetic field and temporal variations of the dynamo families. J. Geophys. Res. 96, 3923-3933.

McFadden, P.L., Merrill, R.T., McElhinny, M.W., 1988. Dipole/quadrupole family modeling of paleosecular variation. J. Geophys. Res. 93, 11583-11588

Opdyke, N., Hall, M., Mejia, V., Huang, K., Foster, D., 2006. The time-averaged field at Ecuador: results from the equator. Geochem. Geophys. Geosyst. 7, doi:10.1029/2005GC001221.

Opdyke, N.D., Henry, K.W., 1969. A test of the Dipole Hypothesis. Earth Planet. Sci. Lett. 6, 139-151.

Piccirillo, E., Melfi, A., Comin-Chiaramonti, P., Bellieni, G., Ernesto, M., Marques, L. Nardy, A., Paca, I., Roisenberg, A., Stolfa, D. (Eds.), 1988. Continental Flood Volcanism from the Paranaá Basin (Brazil). Continental Flood Basalts. Kluwer Academic Publishers, Dordrecht.

Plenier, G., Camps, P., Henry, B., Nicolaysen, K., 2002. Palaeomagnetic study of Oligocene (24-30 Ma) lava flows from the Kerguelen Archipelago (southern Indian Ocean): directional analysis and magnetostratigraphy. Phys. Earth Planet. Int. 133, 127-146.

Prévot, M., McWilliams, M., 1989. Paleomagnetic correlation of the Newark Supergroup volcanics. Geology 17, 1007-1010. 
Quidelleur, X., Couortillot, v., 1996. On low-degree spherical harmonic models of paleosecular variation. Phys. Earth Planet. Int. 95, 55-77.

Raposo, M.I.B., Ernesto, M., 1995. An early Cretacous paleomagnetic pole from Ponta Grossa dikes (Brazil): implications for the Sourth American Mesozoic apparent polar wander path. J. Geophys. Res. 100, 20095-20109.

Renne, P.R., Deckart, K., Ernesto, M., Feraud, G., Piccirillo, E.M., 1996. Age of the Ponta Grossa dike swarm (Brazil), and implications to Paranaflood volcanism. Earth Planet. Sci. Lett. 144 (1-2), 199-211.

Riisager, P., Knight, K., Baker, J., Peate, I., Al-Kadasi, M., Al-Subbary, A., Renne, P., 2005. Paleomagnetism and ${ }^{40} \mathrm{Ar} /{ }^{39} \mathrm{Ar}$ geochronology of Yemeni Oligocene volcanics: implications for timing and duration of Afro-Arabian traps and geometry of the Oligocene paleomagnetic field. Earth Planet. Sci. Lett. 237, 647-672.

Riisager, P., Riisager, J., Abrahamsen, N., Waagstein, R., 2002. Thellier palaeointensity experiments on Faroes flood basalts: technical aspects and geomagnetic implications. Phys. Earth Planet. Int. 131 (2), 91-100.

Roberts, P., Stix, M., 1972. $\alpha$-Effect dynamos, by the Bullard-Gellman formalism. Astron. Astrophys. 18, 453-466.

Schneider, D.A., Kent, D.V., 1990. Testing models of the tertiary paleomagnetic field. Earth Planet. Sci. Lett. 101, 260-271.

Selkin, P., Tauxe, L., 2000. Long-term variations in paleointensity. Philos. Trans. R. Soc. Lond. 358, 1065-1088.

Tan, X., Kodama, K., 1998. Compaction-corrected inclinations from southern California Cretaceous marine sedimentary rocdks indicate no paleolatitudinal offse for the Peninsular ranges terrane. J. Geophys. Res. 103, 27,169-27192,27192.

Tan, X., Kodama, K., 2002. Magnetic anisotropy and paleomagnetic inclination shallowing in red beds: evidence from the Mississippian Mauch Chunk Formation. Pennsylvania. J. Geophys. Res. 107, 2311, doi:10.1029/2001JB001636.

Tan, X., Kodama, K., Gilder, S., Courtillot, V., 2007. Rock magnetic evidence for inclination shallowing in the Passaic Formation red beds from the Newark basin and systematic bias of Late Triaassic apparent polar wander path for North America. Earth Planet. Sci. Lett. 254, 345-357.

Tan, X.D., Kodama, K.P., Chen, H.L., Fang, D.J., Sun, D.J., Li, Y.A., 2003. Paleomagnetism and magnetic anisotropy of Cretaceous red beds from the Tarim basin, northwest China: Evidence for a rock magnetic cause of anomalously shallow paleomagnetic inclinations from central Asia. J. Geophys. Res.-Solid Earth 108 (B2).

Tarduno, J A 1990. Absolute inclination values from deep sea sediments: a reexamination of the Cretaceous Pacific record. Geophys. Res. Lett. 17, 101-104.

Tauxe, L., 1998. Paleomagnetic Principles and Practice. Kluwer Academic Publishers, Dordrecht.

Tauxe, L., Kent, D.V., 1984. Properties of a detrital remanence carried by hematite from study of modern river deposits and laboratory redepostion experiments. Geophys. J. Roy. Astr. Soc. 77, 543-561.

Tauxe, L., Kent, D.V., 2004. A simplified statistical model for the geomagnetic field and the detection of shallow bias in paleomagnetic inclinations: was the ancient magnetic field dipolar? In: Channell, J.E.T., Kent, D.V., Lowrie, W., Meert, J. (Eds.), In: Timescales of the Paleomagnetic Field, vol. 145. American Geophysical Union, Washington, D.C, pp. 101-116.

Vandamme, D., 1994. A new method to determine paleosecular variation. Phys. Earth Planet. Int. 85, 131-142.

Vandamme, D., Courtillot, V., 1992. Paleomagnetic constraints on the structure of the Deccan traps. Phys. Earth Planet. Int. 74, 241-261.

Vandamme, D., Courtillot, V., Besse, J., Montigny, R., 1991. Plaeomagnetism and age determination of the Deccan traps (India): results of tea Napur-bombay traverse and review of earlier work. Rev. Geophys. 29, 159-190.

Vaughn, J., Kodama, K.P., Smith, D., 2005. Correction of inclination shallowing and its tectonic implications: the Cretaceous Perforada formation, Baja California. Earth Planet. Sci. Lett. 232, 72-82. 